\title{
Applications of copper nanoparticles for colorimetric detection of dithiocarbamate pesticides
}

\author{
Saima Ameen Ghoto ${ }^{1}$ Muhammad Yar Khuhawar ${ }^{1} \cdot$ Taj Muhammad Jahangir $^{1} \cdot$ Jamal ul Din Mangi $^{2}$
}

Received: 4 November 2018 / Accepted: 21 February 2019 / Published online: 4 March 2019

(c) The Author(s) 2019

\begin{abstract}
In this report an expeditious, manageable and uncomplicated advancement has been demonstrated in the field of nanoparticles for sensing dithiocarbamates (DTCs) Ziram, Zineb, and Maneb pesticides in environment and juice samples using cetyltrimethyl ammonium bromide (CTAB)-capped copper nanoparticles (CTAB-Cups) as colorimetric probe. The probe was prepared in aqueous solvent using CTAB and hydrazine monohydrate. Localized surface plasmon resonance band of the prepared sensor was scanned by UV-visible spectrophotometer. Further Fourier-transform infrared spectroscopy (FTIR), scanning electron microscopy, energy-dispersive X-ray spectroscopy (EDX), zeta potential and dynamic light scattering (DLS) techniques were employed to reveal the interaction, functionality, surface characteristics and particle size. Probe was used competently for colorimetric sensing of Ziram, Zineb, and Maneb belonging to the DTCs group of pesticides. Sudden change in color from reddish wine to yellow was noted visibly and monitored on spectrophotometer, FTIR, EDX, zeta potential and DLS. The probe indicated very susceptible and selective colorimetric detection of DTCs within the range of 97.9-489.3 ng/ml, 8.8-44.1 ng/ml and 8.4-42.4 ng/ml for Ziram, Zineb and Maneb. The designed method yielded very rapid and organized procedure for detection of DTCs with minimal sample preparations. The method was used for the analysis of DTCs spiked tap water, tomato extract, mango juice, and recoveries of DTCs were obtained within $95.8-108.5 \%$ with relative standard deviation within $0.14-1.11 \%$.
\end{abstract}

Keywords Copper nanoparticles $\cdot$ Colorimetric sensor $\cdot$ Dithiocarbamate $\cdot$ Pesticides

\section{Introduction}

The distinctive optical properties of the noble metallic nanoparticles $(\mathrm{Au}, \mathrm{Ag}$, and $\mathrm{Cu})$ have made them an irresistible prospect in miscellaneous applications, comprising of biotechnology, electronics, optical devices, sensors, catalyses [1] as well as in pharmaceuticals [2-5] and in textile [6]. Due to wide applications of noble metal nanoparticles, numbers of methods have been developed to synthesize NPs with variation in shape, size and topography [7]. Currently, copper is gaining application in the fields of medicines, optics, electronics, antimicrobial, nanofluids, efficient catalyst in production of lubricants and conductive

Saima Ameen Ghoto

saimaghoto99@gmail.com

1 Institute of Advanced Research Studies in Chemical Sciences, University of Sindh, Jamshoro 76080, Pakistan

2 Institute of Plant Sciences, University of Sindh, Jamshoro 76080, Pakistan films [8-15]. However, colorimetric applications of copper nanoparticles are rarely found. Furthermore, low cost and easy availability of copper as compared to precious metal $\mathrm{Au}, \mathrm{Ag}, \mathrm{Pt}$ offers it as a suitable candidate [16]. One of the major problems in utilizing CuNPs in sensor application is their susceptibility to oxidation when exposed to air. In this regard various methods have been established to synthesize CuNPs by alternating the suitable parameters and under inert atmosphere $[17,18]$.

Dithiocarbamates are one of the frequently used sulfur-containing organic compounds [19]. They have wide spread applications in rubber manufacture, antioxidants [20], as antislime in paper making and also in production of sugar [21]. In this regard the amount consumed annually is estimated between 25,000 and 35,000 metric tons [22, 23]. Dithiocarbamates are categorized in different classes on the basis of their carbon skeleton and properties such as; ethylenebisdithiocarbamate (EBDTC) comprises of mancozeb, nabam, metiram, zineb, and maneb: propylenebisdithiocarbamate (PEBDTC) comprises of propineb: 
dimethyldithiocar-bamate (DMDTC) includes ziram, ferbam. Another category belonging to DTCs is tetramethylthiuram disulfide which comprises thiram pesticide [24].

The vast use of these pesticides has raised some environmental noxiousness and health antipathetic effects leading to chronic health problems, organ toxicity, effects on central and peripheral nervous system and thyroid functioning [21]. Due to all these, determination of these DTCs pesticides is taken into consideration to alleviate them from exposure to human beings and water contamination. Numerous analytical techniques have been employed to determine the pesticides such as; chromatography, flow-injection method, spectrometry, polarography, biosensor $[20,25,26]$ and also through advanced techniques, LC-MS [27], LC-MS/ MS [28], GC-flame photometric detection [29], MS [30], hydrophilic injection liquid chromatography (HILC) [31] and HPLC-DAD [32]. Most commonly dithiocarbamates are determined by $\mathrm{CS}_{2}$ evolution procedure being lengthy and a less-sensitive method. On the other hand, HPLC, GC, MS etc. being sensitive advanced techniques, they are cost effective, time-consuming, have lengthy processing, and require special additives. With the increasing use of dithiocarbamates in agriculture, there is need for the design of highly sensitive discriminatory and speedy method for their determination. In this regard, metal nanoparticles have attracted considerable attention as colorimetric sensors because of their simplicity and efficiency. Noteworthy gold and silver nanoparticles have been used in the detection of dithiocarbamates [33-37] with abrupt color change visible to naked eye. To the best of our knowledge any procedure is reported on colorimetric sensing of DTC pesticides using copper nanoparticles.

In present work CTAB-CuNPs-based colorimetric sensor for DTCs has been established due to its simple, speedy, and subtle nature. The practical potency of the sensor was demonstrated by sensing DTCs in environmental (water) and juice sample (tomato vegetable and commercial mango beverage). This scheme examines the method for sensing of dithiocarbamates ziram, zineb and maneb and compares with reported procedures using precious metal gold or silver nanoparticles.

\section{Experimental}

Hydrochloric acid $(\mathrm{HCl})$, copper chloride dihydrated $\left(\mathrm{CuCl}_{2} \cdot 2 \mathrm{H}_{2} \mathrm{O}\right)$, hydrazine monohydrate $\left(\mathrm{N}_{2} \mathrm{H}_{4} \cdot \mathrm{H}_{2} \mathrm{O}\right)$, ethylenediamine $\left(\mathrm{C}_{2} \mathrm{H}_{8} \mathrm{~N}_{2}\right)$, manganese sulfate $\left(\mathrm{MnSO}_{4}\right)$, zinc acetate $\left(\mathrm{ZnC}_{4} \mathrm{H}_{6} \mathrm{O}_{4}\right)$, sodium bicarbonate $\left(\mathrm{NaHCO}_{3}\right)$, potassium chloride $(\mathrm{KCl})$, ammonium chloride $\left(\mathrm{NH}_{4} \mathrm{Cl}\right)$, ammonium acetate $\left(\mathrm{C}_{2} \mathrm{H}_{7} \mathrm{NO}_{2}\right)$ and dimethyl sulfoxide $\left(\mathrm{C}_{2} \mathrm{H}_{6} \mathrm{OS}\right)$ were obtained from Merck, Darmstadt, Germany.
Cetyltrimethyl ammonium bromide $\left(\mathrm{C}_{19} \mathrm{H}_{42} \mathrm{Br}\right)$, sodium chloride $(\mathrm{NaCl})$ and sodium acetate $\left(\mathrm{NaC}_{4} \mathrm{H}_{7} \mathrm{NO}_{2}\right)$ were purchased from Scharlu, Spain. Magnesium carbonate was obtained from Fluka, Switzerland. All the solutions used in experimental work were prepared in distilled water. Glasswares were cleaned in nitric acid $\left(\mathrm{HNO}_{3}\right)(0.1 \mathrm{~N})(\mathrm{E}$, Merck Germany) and then washed with double distilled water and dried in preheated oven $(110 \dot{\mathrm{C}})$.

\section{Preparation of copper nanoparticles (CuNPs)}

Preparation of copper nanoparticles was accompanied by following reported method [38] with some modifications via wet chemical reduction method. In a typical synthetic method $4 \mathrm{ml}$ of $(0.03 \mathrm{M}) \mathrm{CuCl}_{2} \cdot 2 \mathrm{H}_{2} \mathrm{O}$ solution was diluted with $76 \mathrm{ml}$ of distilled water and obtained a light bluish colored solution. After that, $12 \mathrm{ml}$ of $1 \%$ CTAB solution was added in bluish copper salt solution. The mixture was stirred continuously and followed by addition of hydrazine monohydrate (64-65\% reagent grade, $98 \%)(8 \mathrm{ml})$ to start the reduction from $\mathrm{Cu}^{2+}$ salt to $\mathrm{Cu}^{0}$. The temperature of the reaction mixture was held at $80{ }^{\circ} \mathrm{C}$. Color change was observed time-to-time from light bluish to wine reddish with number of transitional phases. Reddish color indicated the formation of CuNPs assisted by hydrazine monohydrate which served as reducing agent. The solution mixture was stirred for $30 \mathrm{~min}$ more to assure the complete reduction and capping of CuNPs. Temperature of the reaction mixture was maintained up to $80{ }^{\circ} \mathrm{C}$ during stirring also. The $\mathrm{pH}$ of the solution was measured and was 11.3.

\section{Characterization}

All ultraviolet-visible spectra of CuNPs samples were monitored by 220 Hitachi double-beam spectrophotometer (Hitachi (Pvt) Ltd, Tokyo, Japan) in range of 800-400 nm using dual $1 \mathrm{~cm}$ silica cuvettes. The FTIR spectra were recorded on Nicolet Atavar 330 (Thermo Nicolet Corporation, USA) with attenuated total reflectance accessary (smart partner) within $4000-600 \mathrm{~cm}^{-1}$. Orion $420 \mathrm{~A} \mathrm{pH}$ meter (Orion Research Inc., Boston USA) was used to measure the $\mathrm{pH}$ of the solutions. The structural features (SEM and EDX) of the synthesized NPs with and without interaction of pesticides were recorded on scanning electron microscope (JEOL JSM-6490LV) at the center of Pure and Applied Geology, University of Sindh Jamshoro. The zeta potential and dynamic light scattering (DLS) size distribution of CTAB-CuNPs with and without addition of pesticides were determined using Zetasizer Nano-ZS Malvern instrument Inc, London UK at the department of Metallurgy and Materials Engineering, Mehran University of Engineering and Technology, Jamshoro. 


\section{Preparations of dithiocarbamate ziram, zineb and maneb pesticides}

$\mathrm{Zn}$ and $\mathrm{Mn}$ salts of dithiocarbamates pesticides were prepared by reported method [39]. In a nutshell zinc salt of dimethyldithiocarbamate (Ziram) and zinc and manganese salts of ethylenebis dithiocarbamates (Zineb and Maneb) were synthesized from the reaction of primary amine (ethylenediamine) and secondary amine (dimethyl amine) with carbon disulfide in alkaline medium and later reaction was made with salts of zinc and manganese such as zinc acetate and manganese sulfate separately to form their corresponding metal complexes of Ziram, Zineb and Maneb pesticides. The reaction temperature was maintained below $40{ }^{\circ} \mathrm{C}$. The solutions of pesticides so formed were kept at $4{ }^{\circ} \mathrm{C}$ when not in use. All solutions for pesticides were prepared in dimethyl sulfoxide (DMSO) and water.

\section{Method development using diethyldithiocarbamate (DEDTC)}

Initially, the probe was tested on the general reagent diethyldithiocarbamte (DEDTC) (belonging to the same category of dithiocarbamate group and is highly soluble in water and other polar solvents) to observe the potential of interaction with the change in plasmon and color. Based on this interaction, parameters such as, $\mathrm{pH}$ and time were optimised. Using this general reagent, choloroform test was also carried out to identify the type of interaction between probe and dithiocarbamtes. Latter results were checked and confirmed using DTC pesticides Ziram, Zineb and Maneb. After optimisation of parameters the probe was applied on the pesticides Ziram, Zineb and Maneb.

\section{Chloroform test}

A critical examination of chemical nature of dithiocarbamates with CTAB-stabilized copper NPs was performed using chloroform reagent. For this study two screw-capped sample vials were taken and in one was added $2 \mathrm{ml}$ of CuNPs and in another solution of copper (11) chloride $(2 \mathrm{ml})$ containing ( $50 \mu \mathrm{g} \mathrm{Cu}$ (II)) was added, followed by $1 \mathrm{ml}$ borate buffer solution $\mathrm{pH} 8$ and $1 \mathrm{ml}$ of DEDTC reagent in each vial separately. Both the solutions were made to $10 \mathrm{ml}$ and mixed well. Copper (II) solution developed yellow precipitates, but the solution of CuNPs remained clear. $2 \mathrm{ml}$ chloroform each was added to both the solutions and contents were mixed well. The precipitates of copper (II) were dissolved and most of the color transferred to the chloroform layer. A similar transfer of the color to organic phase was not observed in case of CuNPs. Same observation was also seen with Ziram, Zineb, and Maneb.

\section{Sensing of DTCs by CTAB-CuNP probe}

To inspect the sensing potency of CTAB-CuNP as probe, $2 \mathrm{ml}$ of CuNPs was taken in sample vial with $1 \mathrm{ml}$ of Ziram $(0.16-0.016 \mathrm{mM})$, Zineb $(0.16-0.0016 \mathrm{mM})$ or Maneb $(0.16-0.0016 \mathrm{mM})$ separately. Volume was adjusted to $10 \mathrm{ml}$ with double distilled water. The contents were agitated and mixed well. The color change and spectra were monitored on spectrophotometer in the range of 400-800 $\mathrm{nm}$. Images were also captured.

\section{Analytical procedure for the determination of Ziram, Zineb, and Maneb pesticide}

DTCs pesticides were determined quantitatively at $490 \mathrm{~nm}$ or better ratio of absorbance at 490:570 nm against concentration. For this $2 \mathrm{ml}$ CTAB-CuNPs $(1.2 \mathrm{mM})$ was taken in a $10 \mathrm{ml}$ flask with $1 \mathrm{ml}$ of sodium tetraborate-boric acid buffer of $\mathrm{pH}$ 8. The pesticides in the final concentration range of $97.8-978.5 \mathrm{ng} / \mathrm{ml}, 8.8-88.2 \mathrm{ng} / \mathrm{ml}$ and $8.4-84.8 \mathrm{ng} / \mathrm{ml}$ for Ziram, Zineb or Maneb was then added and volume was adjusted to $10 \mathrm{ml}$ with distilled water. Change in color intensity was seen visibly with the rise in concentration of pesticides and samples were monitored on spectrophotometer after $45 \mathrm{~min}$.

\section{Practical utility of probe in environment and juice sample}

The tap water samples were collected from laboratory (Institute of Advanced Research Studies in Chemical Sciences, Jamshoro Pakistan). The sample was filtered and $3 \mathrm{ml}$ of tap water was spiked with $1 \mathrm{ml}$ of Ziram $(0.016 \mathrm{mM}), 1 \mathrm{ml}$ of each Zineb or Maneb $(0.0016 \mathrm{mM})$ separately and total volume was made to $10 \mathrm{ml}$.

For tomato (purchased from local market of Jamshoro), extract was collected as reported method [40] with some modification. The tomato was soaked in distilled water, afterwards homogenized in grinder mixer for $30 \mathrm{~s} .10 \mathrm{~g}$ was added to $25 \mathrm{ml}$ of distilled water mixed well and filtered. On the remaining residue left over the filter paper, $25 \mathrm{ml}$ of distilled water was again added. Finally, total extract solution was made to $100 \mathrm{ml}$. Then $1 \mathrm{ml}$ from this extract was taken and spiked with $1 \mathrm{ml}$ of Ziram, Zineb or Maneb pesticides separately with the total volume made up to $10 \mathrm{ml}$.

Similarly, for commercial mango drink $10 \mathrm{ml}$ of mango juice was diluted to $100 \mathrm{ml}$ with distilled water. Then $1 \mathrm{ml}$ from this solution was taken and added to Ziram $(0.016 \mathrm{Mm})$, Zineb $(0.0016 \mathrm{mM})$ and Maneb $(0.0016 \mathrm{mM})$ $(1 \mathrm{ml})$ and volume was made up to $10 \mathrm{ml}$.

Different concentrations of aforementioned samples were taken within the calibration range of Ziram, Zineb and Maneb and analyzed using analytical procedure. The $\%$ 
Fig. 1 The chemical structures of pesticides inspected

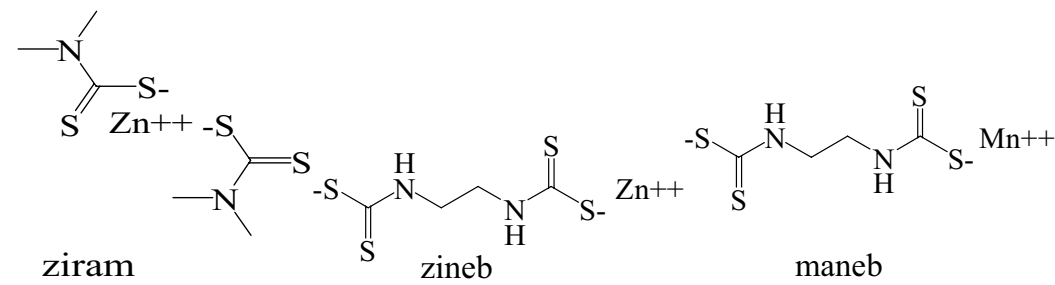

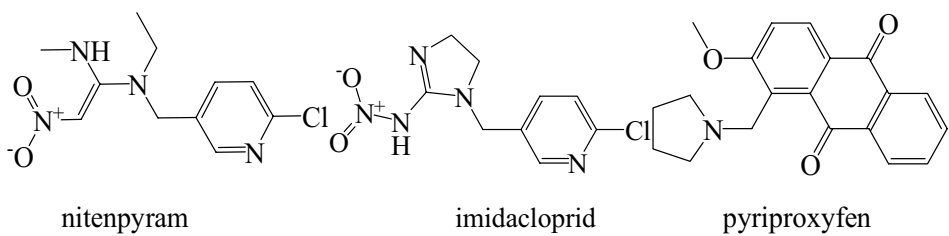

$\mathbf{a}$

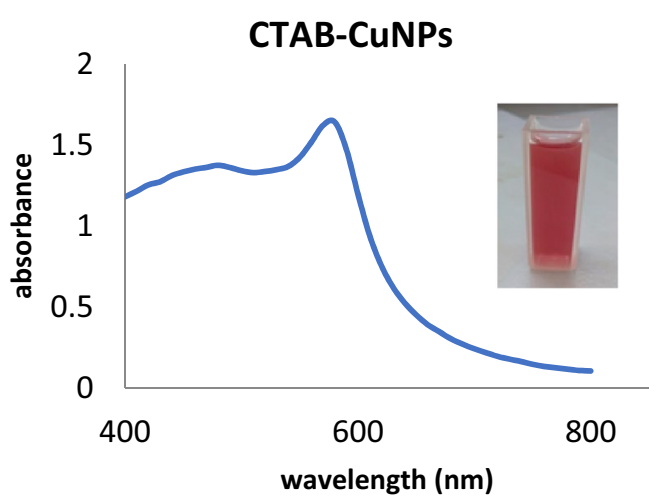

c

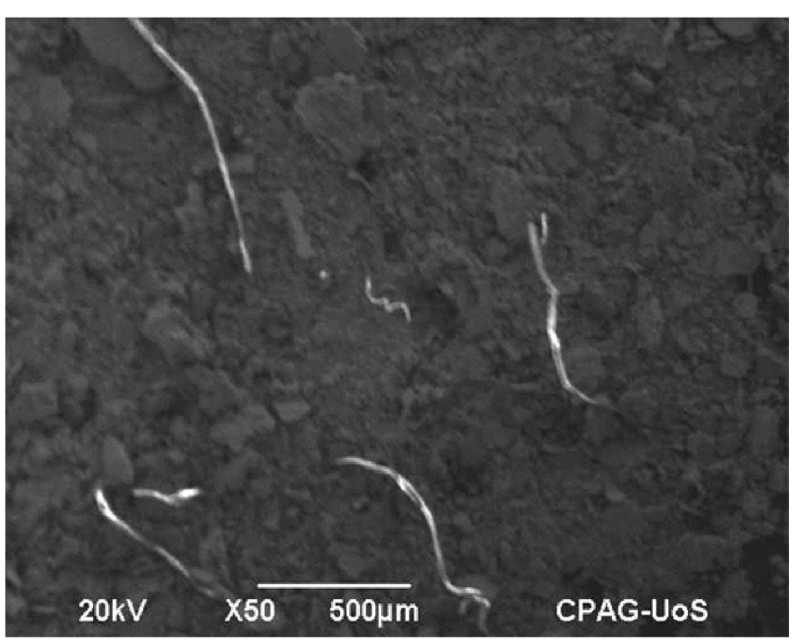

b

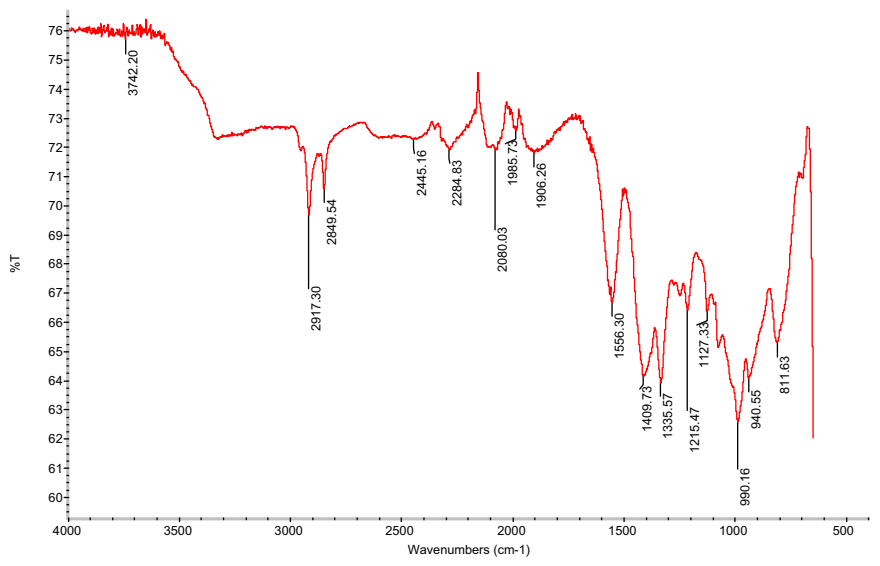

d

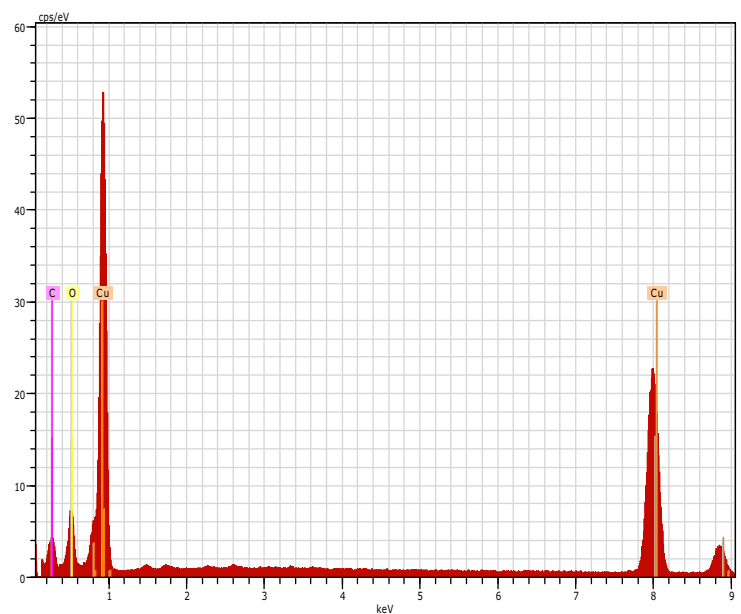

Fig. 2 a UV-visible spectrum, b FTIR, c SEM image and d EDX spectrum of CTAB-stabilized copper nanoparticles

recoveries were then calculated. The quantitation was made from linear regression equation. Their recoveries were calculated by following formula,
$\%$ Recovery = Amount of pesticides calculated/ Amount of pesticide added $\times 100$ 
Fig. 3 Absorption spectrum of probe on interaction with different molar concentration of pesticides ziram, zineb and maneb

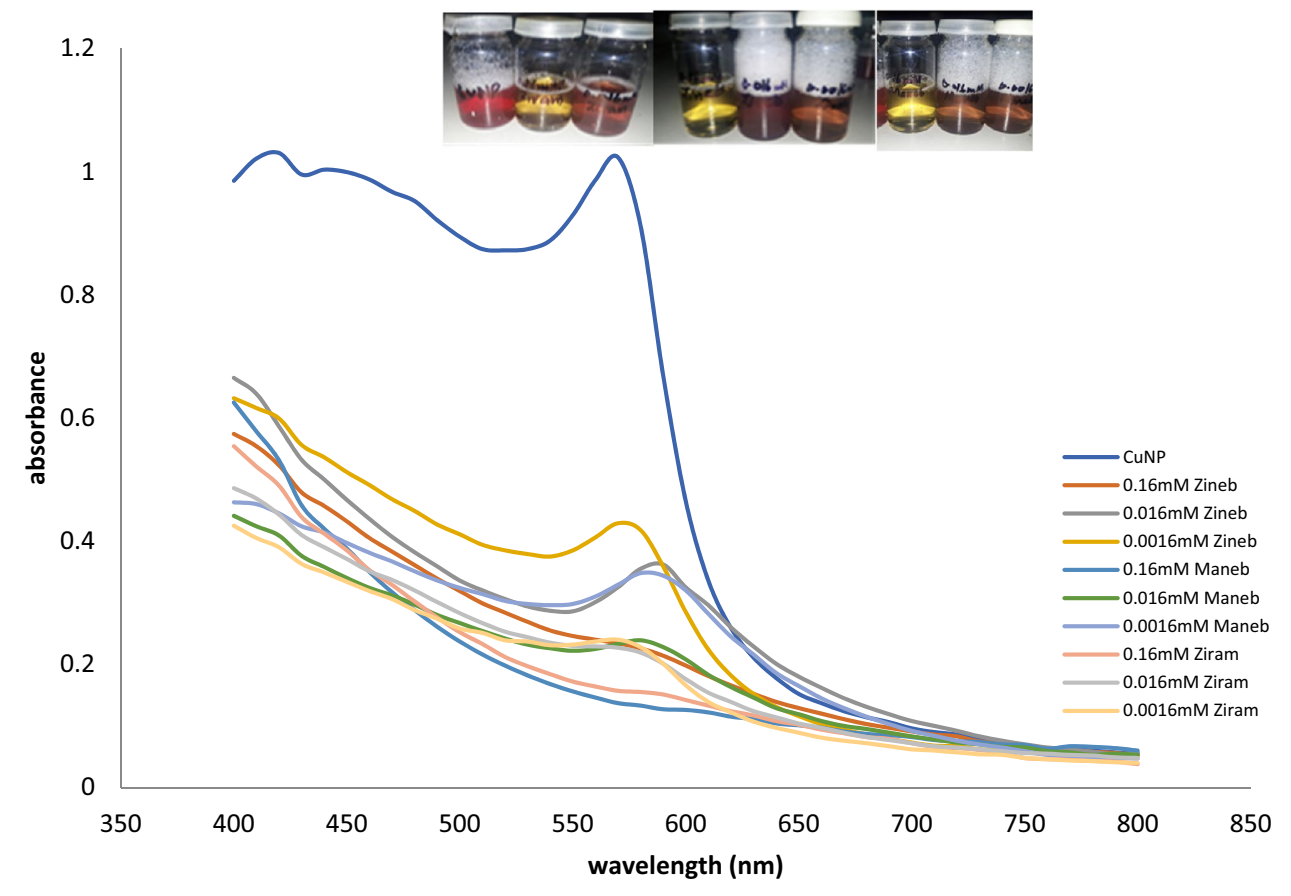

\section{Interference study of ions and pesticides}

Selectivity of the as-prepared probe was determined in presence of different interferents including ions $\left(\mathrm{Ca}^{2+}, \mathrm{K}^{+}, \mathrm{Al}^{3+}\right.$, $\mathrm{Cl}^{-}, \mathrm{NO}_{3}{ }^{-}, \mathrm{CO}_{3}{ }^{2-}$ ) and pesticides (nitenpyram, imidacloprid, and pyriproxyfen) on the determination of $293.6 \mathrm{ng} /$ $\mathrm{ml}$ of Ziram and $26.5 \mathrm{ng} / \mathrm{ml}$ of Zineb under similar working conditions and at $\mathrm{pH} 8$ using borate buffer. The results obtained were compared with the standards without the presence of interfering ions or pesticides.

Nitenpyram, imidacloprid, and pyriproxyfen were examined both separately and in mixtures with the DTCs to evaluate their reciprocal action with the CuNPs and their possible competition to the DTC-induced accumulation of CuNPs. The tolerance limit determined was based on the maximum concentration of interferents causing $\pm 10 \%$ error in the examination of DTC pesticides. Selectivity of the probe was visualized on double-beam spectrophotometer and images were also captured in presence and absence of pesticides mixture in CuNPs. The chemical structures of different pesticides inspected are given in Fig. 1.

\section{Zeta potential and dynamic light scattering (DLS) (size distribution) measurements}

Zeta potential is related to the charge present on the surface of nanoparticles, which greatly effects the stability of particles in colloidal solutions through the electrostatic interaction between particles [41]. The charge and size distribution of CTAB-CuNPs and CTAB-CuNPs interacted with DTCs were measured using Malvern ZS-Nano analyser (Malvern instrument Inc., London U.K). The analysis was carried out at the parameters of temperature of $25^{\circ} \mathrm{C}$. Refractive index of the dispersant was 1.330 , whereas material refractive index was 0.640 . Viscosity of the medium was $0.887 \mathrm{cps}$. For analysis dilute solutions of copper nanoparticles $(0.21 \mathrm{mM})$ and pesticides Ziram, Zineb and Maneb $(0.012 \mathrm{mM})$ were selected, pH 8 was kept fixed with borate buffer. The solutions were stirred and ultrasonicated for $15 \mathrm{~min}$ to breakup any aggregates [42] and then $1-2 \mathrm{ml}$ was transfered to the zeta-disposable cell. All working solutions were made in aqueous solvent. Each experiment was carried out at least three times and their mean values were calculated. Same experimental conditions were kept for DLS measurements of the solutions.

\section{Results and discussion}

First, copper nanoparticles were prepared by wet chemical reduction method, where cetyltrimethyl ammonium bromide was used to protect the exterior of CuNPs and hydrazine monohydrate was used as reducing agent. Color change was from light bluish to wine reddish with intermediate stages and revealed the formation of copper nanoparticles. The prepared CuNPs were characterized by UV-visible spectroscopy, FTIR, SEM, and EDX techniques. Synthesis of CuNPs is one of the challenging tasks because it is highly susceptible to oxidation and is sensitive to air and the oxides phases are thermodynamically more stable. Copper NPs indicated its characteristic UV-visible peak at about $570 \mathrm{~nm}$ (Fig. 2a), presenting efficacious formation of 
a

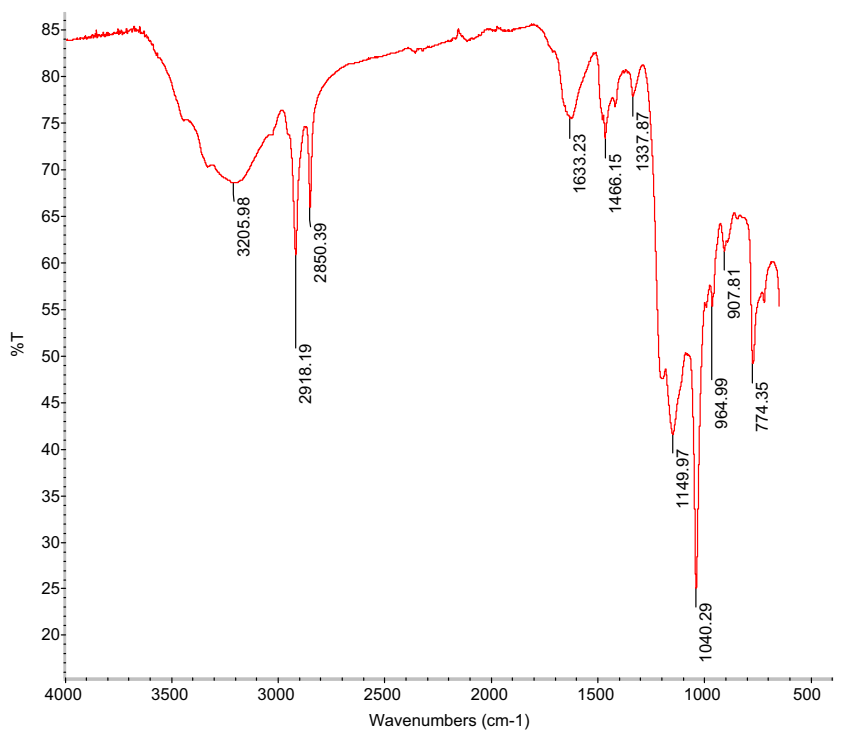

b

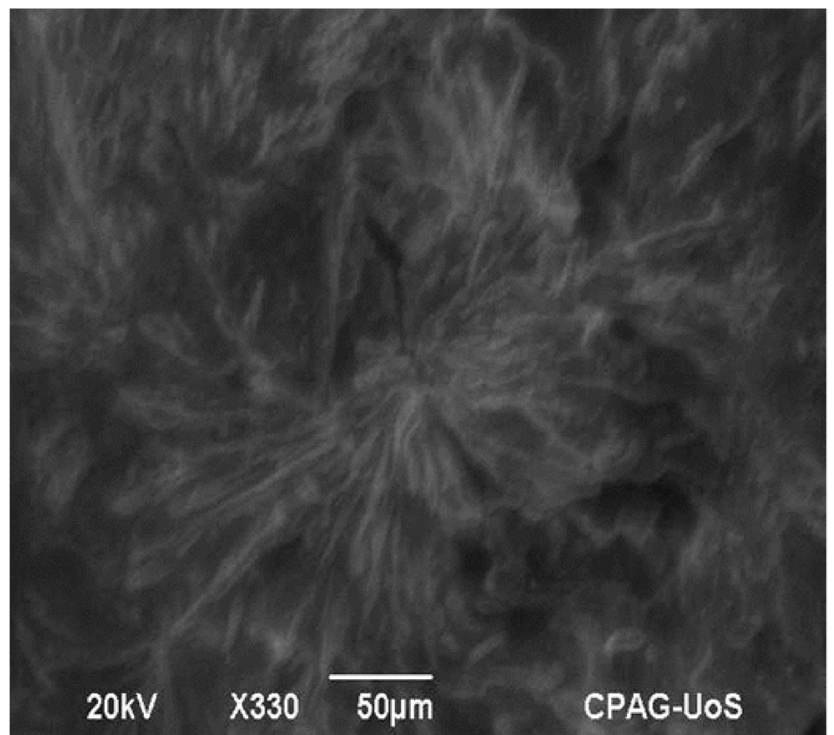

c

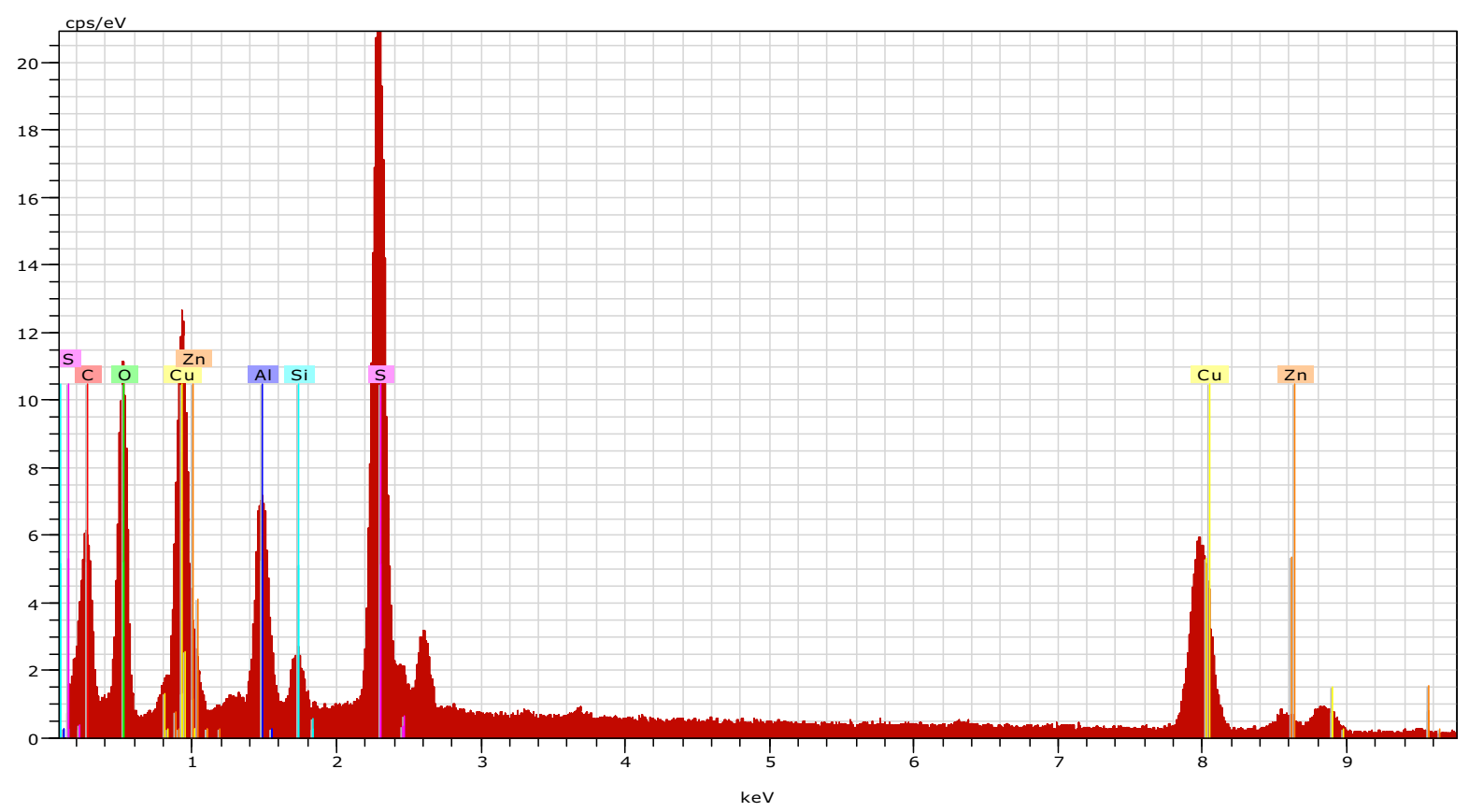

Fig. 4 a FTIR, b SEM image and $\mathbf{c}$ EDX spectrum of Ziram-interacted CTAB-CuNPs

CTAB-stabilized CuNPs [43]. Second most important challenge is to stabilize CuNPs, because NPs agglomerate when free, they communicate with each other and unite together, with the formation of the clusters and extinguish the anticipated properties of NPs [44, 45]. To avoid this risk, a suitable capping agent has remarkable role and CTAB capping agent was used owing to its amphiphilic nature having both hydrophilic and hydrophobic part [46]. A positive charge is created at the surface of CuNPs by hydrophilic part of CTAB, while hydrophobic part creates stearic hindrance to avoid the coagulations and oxidation. The colloidal solution was found to be stable maximally for 1 week. This stability is attributed to the strong hydrophobic interaction of long alkyl chain. 
$\mathbf{a}$

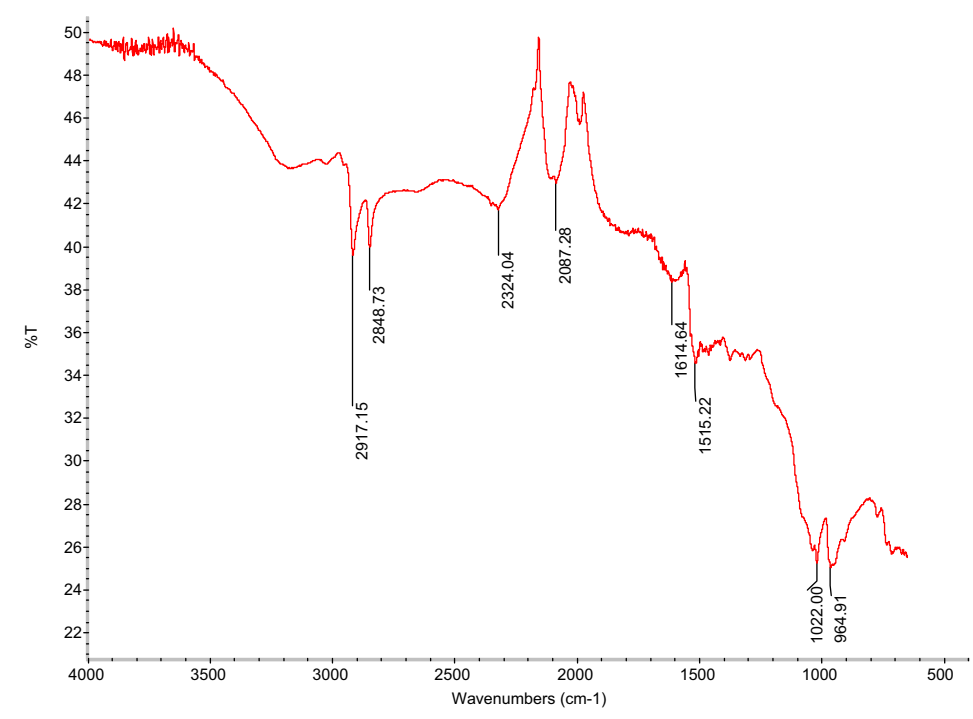

b

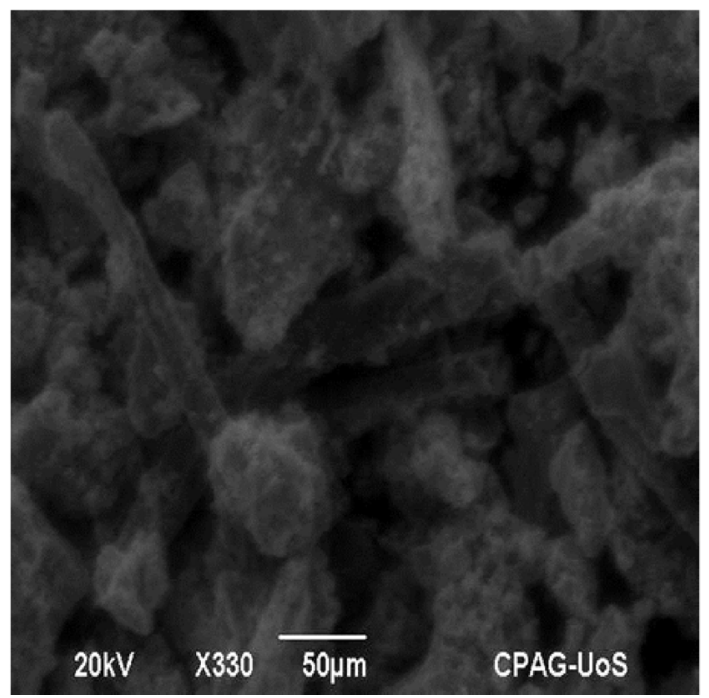

c

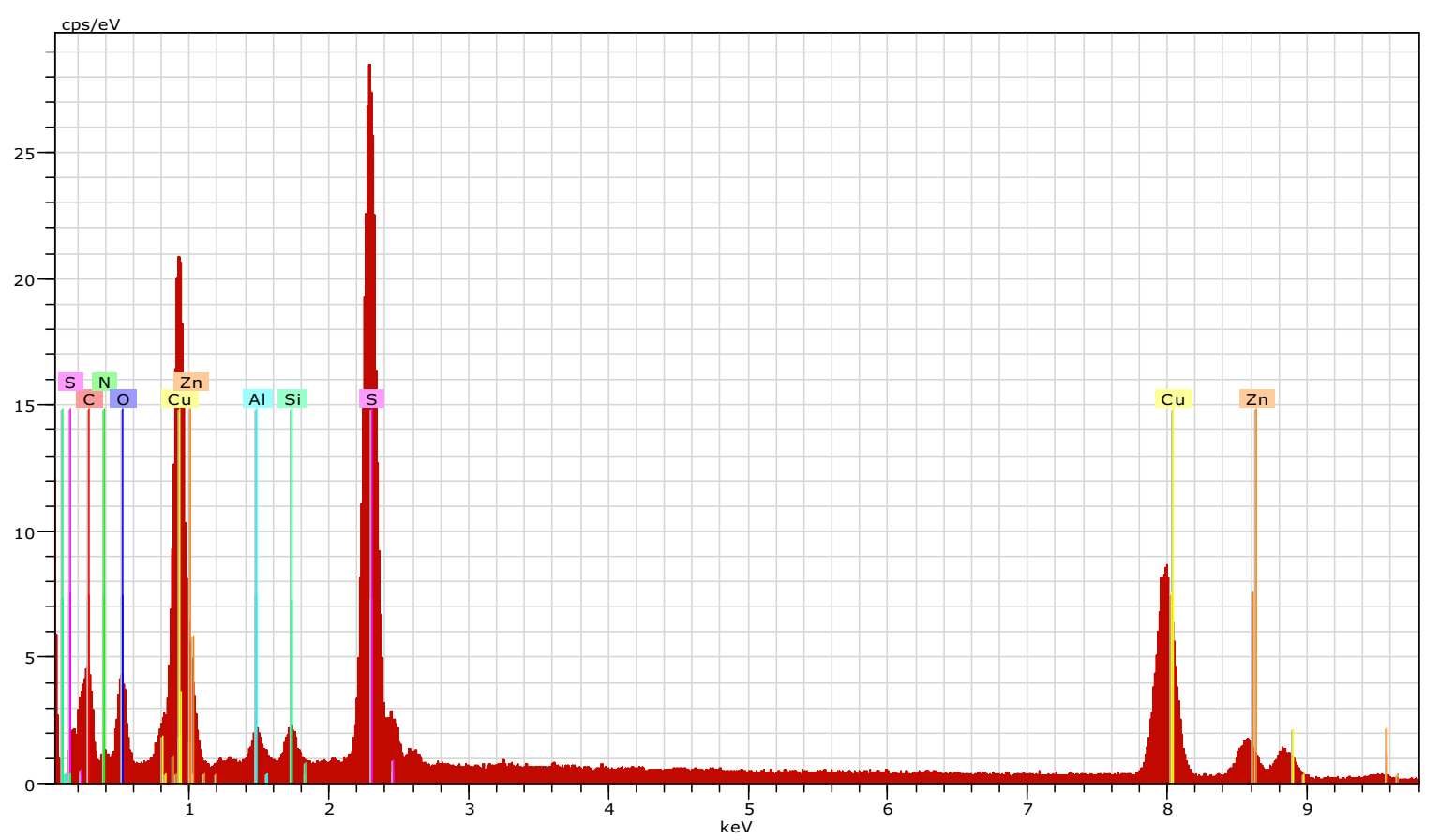

Fig. 5 a FTIR, b SEM image and c EDX image of Zineb-interacted CTAB-CuNPs

FT-IR indicated $\mathrm{C}-\mathrm{H}$ stretching bands observed at $2917-2849 \mathrm{~cm}^{-1}$ and stretching contributed by $\mathrm{N}^{+}-\mathrm{CH}_{3}$ was seen at $1556 \mathrm{~cm}^{-1}$ and $1409 \mathrm{~cm}^{-1}$. Bromide showed its presence at $750 \mathrm{~cm}^{-1}$. This showed the successful assembly of capping agent CTAB on CuNPs (Fig. 2b). The structural features of CTAB-CuNPs were demonstrated by SEM, which showed the rough surface morphology with thin rods on it (Fig. 2c). EDX monitored the elemental compositions of specimen under observation. Results showed the appearance of signal peaks for $\mathrm{Cu}, \mathrm{O}$ and $\mathrm{C}$ element (Fig. 2d). The results achieved for SEM and EDX showed close similarity as reported [47, 48].

The efficiency of sensor to interact with DTC Ziram, Zineb, and Maneb pesticides was monitored on 
a
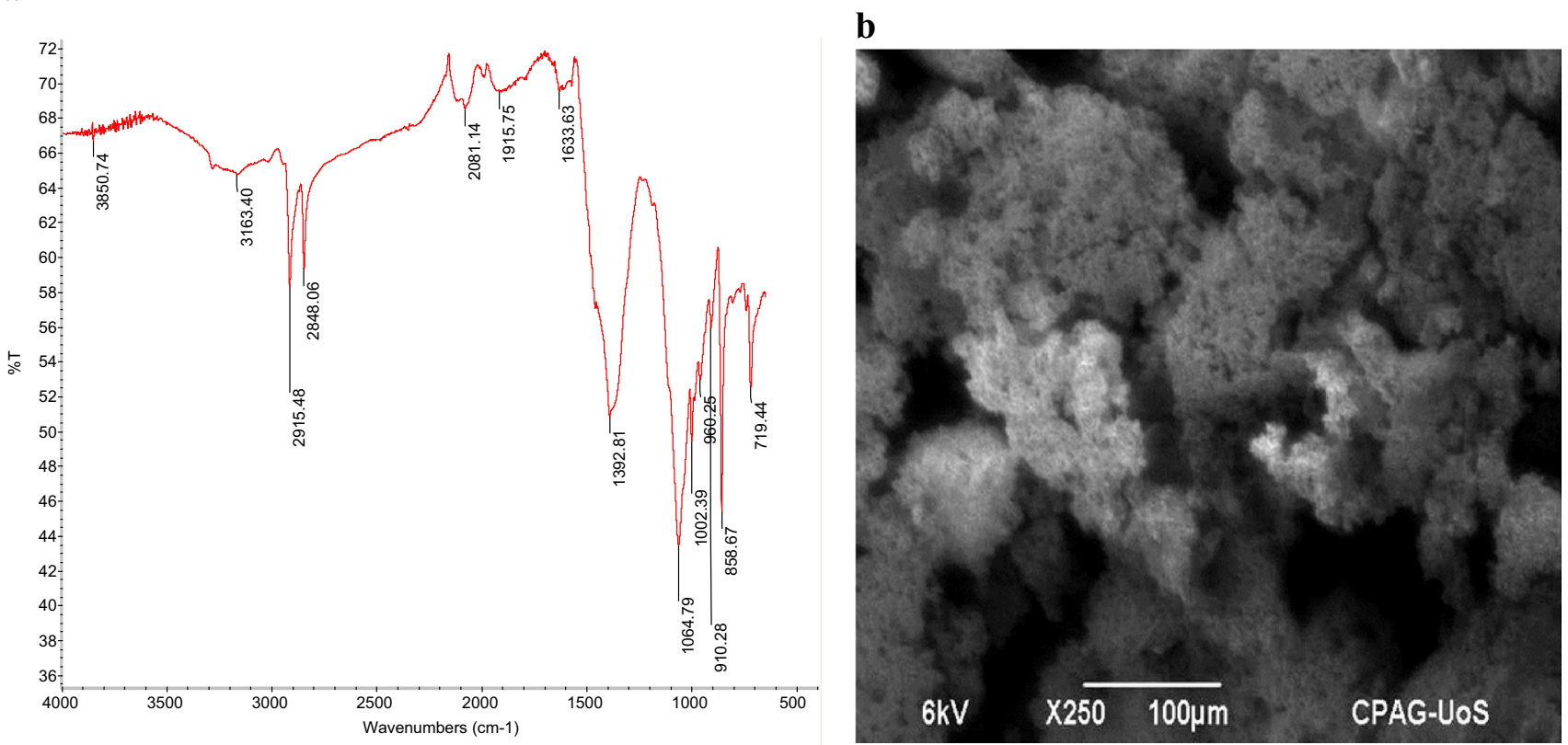

c

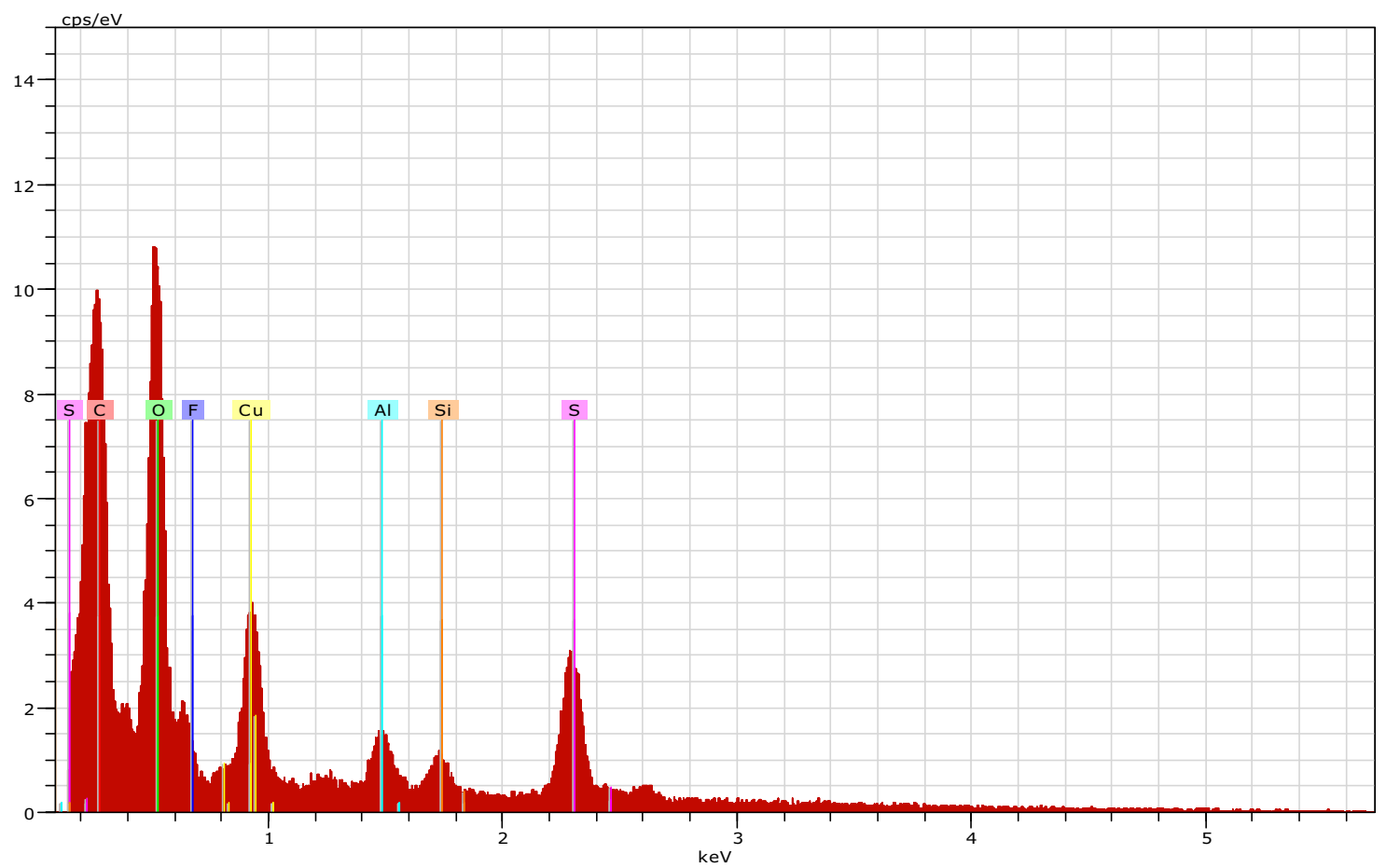

Fig. 6 a FTIR, b SEM image and c EDX image of Maneb-interacted CTAB-CuNPs

spectrophotometer in range 400-800 nm (Fig. 3). Shift in absorbance was noted with the color change from red to yellow and light brownish colloidal (depending upon the concentration of pesticides added) visible to naked eye. It is supposed that small distance between sulfur atoms of DTCs makes it vulnerable for the attraction of ligand with metal elements [49]. Second, DTC has ability to split its sulfide bond when it approaches to colloidal solution of NPs. Therefore, DTC ion is formed which assembled on the surface of the nanoparticles [50]. In addition, 

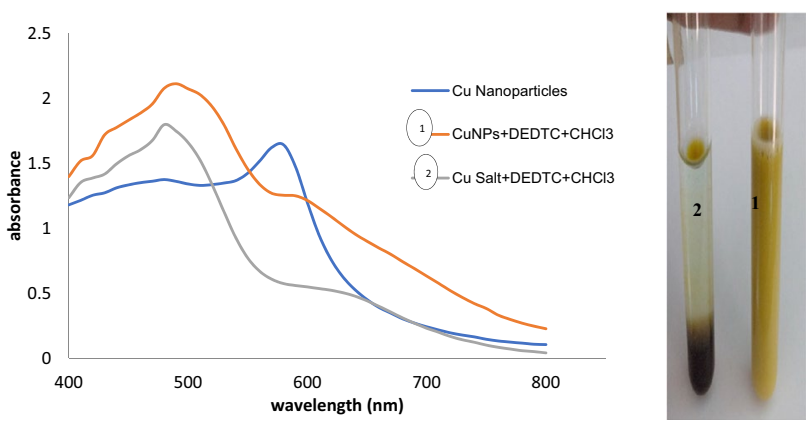

Fig. 7 Chloroform test using general reagent natrium diethyldithiocarbamate to observe the type of interaction, reaction conditions as in experimental

an electrostatic interaction is also found to be established between hydrophilic positive head of the CTAB to the negative sulfides of DTCs [51]. The FTIR of Ziram functionalized on CTAB-CuNPs showed its characteristic peak of N-H at $3200 \mathrm{~cm}^{-1}$.C-H stretching within $2918-2850 \mathrm{~cm}^{-1}$ and $\mathrm{C}=\mathrm{N} / \mathrm{NH}$ vibratory band at $1633 \mathrm{~cm}^{-1}$. Other bands were recorded at $1466-1337 \mathrm{~cm}^{-1}$ contributed by $\mathrm{N}^{+}-\mathrm{CH}_{3}$ of CTAB. C-S of DTC showed its band at $1040 \mathrm{~cm}^{-1}$ (Fig. 4a). SEM image of Ziram interacted CuNPs showed smooth surface with thinner tubule-like structures embedded over it (Fig. 4b). While EDX showed signals for $\mathrm{Cu}, \mathrm{S}, \mathrm{C}, \mathrm{O}$, and $\mathrm{Zn}$. Presence of $\mathrm{S}, \mathrm{C}$ and $\mathrm{Zn}$ is clear indication of interaction of DTCs and CuNPs (Fig. 4c).

Similar FTIR peaks were also recorded for Zineb interacted with CTAB-CuNPs (Fig. 5a). SEM image showed granular topography (Fig. 5b) with the emergence of $\mathrm{Cu}$, $\mathrm{Zn}, \mathrm{O}, \mathrm{S}$, and $\mathrm{C}$ analyzed by EDX technique (Fig. 5c). While the FTIR of Maneb with CTAB-CuNPs indicated its $\mathrm{N}-\mathrm{H}$ stretching peak at $3163 \mathrm{~cm}^{-1}, \mathrm{C}-\mathrm{H}$ bands were seen at $2915-2848 \mathrm{~cm}^{-1}, \mathrm{C}=\mathrm{N} / \mathrm{NH}$ vibratory band at $1634 \mathrm{~cm}^{-1}$ and vibratory band of $\mathrm{N}^{+}-\mathrm{CH}_{3}$ of CTAB was observed at
$1393 \mathrm{~cm}^{-1}$ and a prominent peak of C-S of DTC group was observed at $1065 \mathrm{~cm}^{-1}$ (Fig. 6a). SEM images showed rough-surfaced morphology of maneb pesticide sample (Fig. 6b).Elemental composition determined by EDX indicated presence of $\mathrm{Cu}, \mathrm{S}, \mathrm{C}$, and $\mathrm{O}$ (Fig. 6c).

Through literature survey, it was found that metallic $\mathrm{Cu}$ is highly susceptible for complexation with DTCs [52]. In this regard, chloroform reagent was used to assess the chemical reaction of pesticides with CTAB-CuNPs. Copper (II) when treated with DEDTC reagent indicated precipitate formation, which was extractable in chloroform, whereas CTABCuNPs, when treated with DEDTC or DTC pesticides, yellow color developed, which did not extract in chloroform (Fig. 7). It is pretended that chelates are formed when copper chloride and pesticides are treated together. Charge of the copper salt is neutralized by developing neutral organic

\section{Time effect}

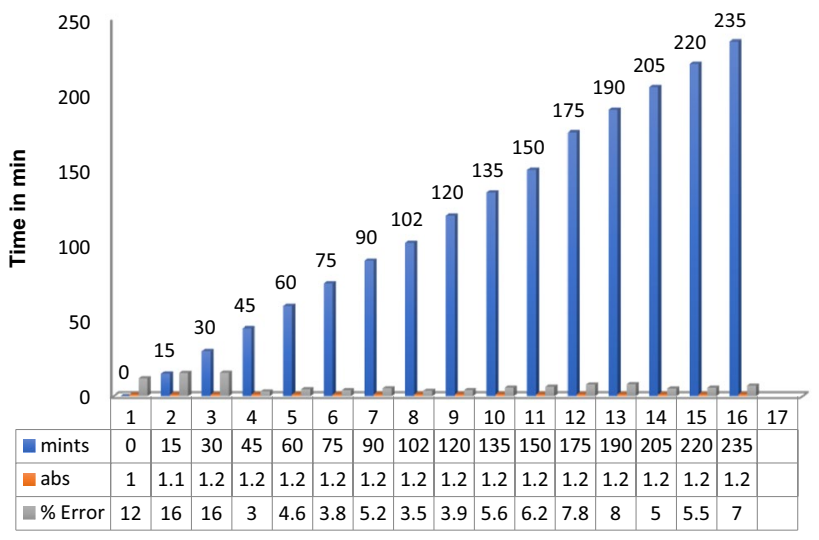

Fig. 9 Time study on stability of NPs with DEDTC

b

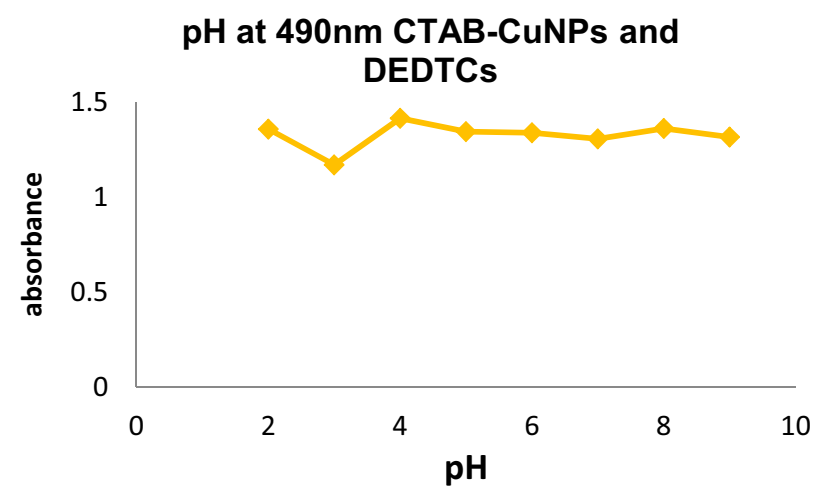

Fig. 8 pH study of copper nanoparticles (a) without and (b) without addition of DEDTC reagent 


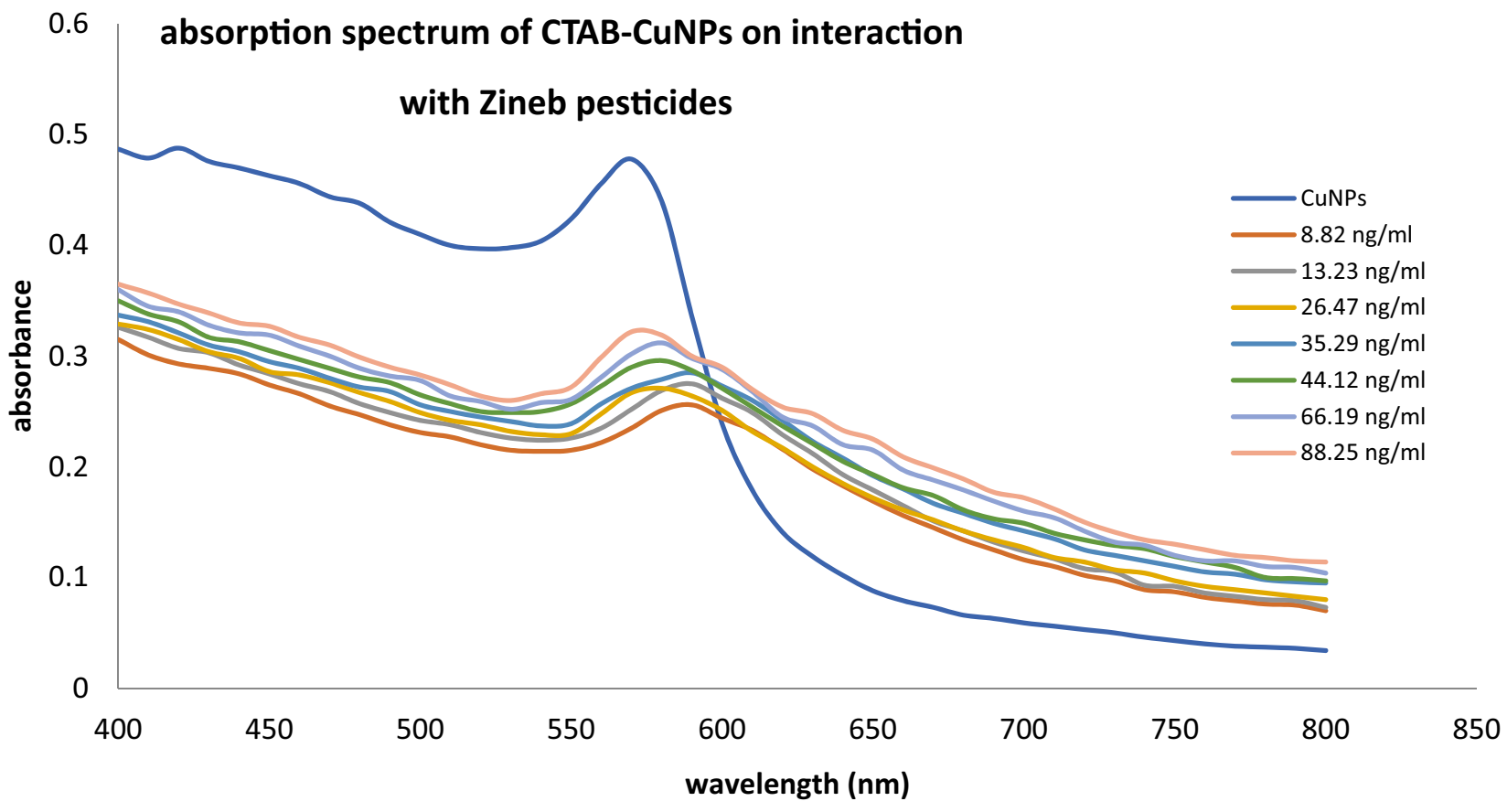

b

\section{Ziram}

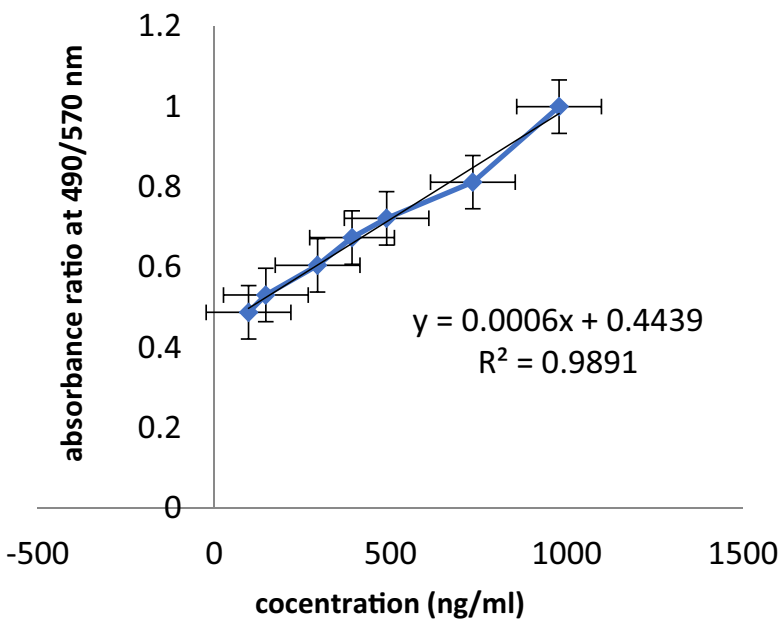

c

Zineb and Maneb

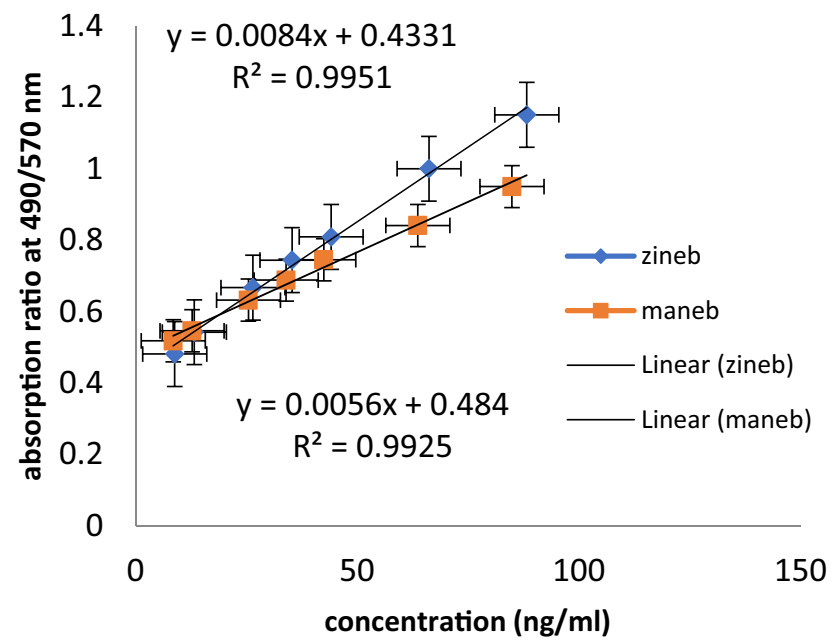

Fig. 10 a Absorption spectra of zineb pesticides and $\mathbf{b}$ linear calibration curves of DTC pesticides at absorbance ratio of $490 / 570 \mathrm{~nm}$

moiety which is therefore extracted in chloroform. In case of copper nanoparticles, no such metal chelation was seen but charged species were formed which organized on the nanoparticles surface via oppositely charged interaction.

Eventually colorimetric response of NPs is highly dependent on the $\mathrm{pH}$ of the solution. Therefore, CuNPs with and without diethyldithiocarbamate (DEDTCs) or DTC pesticides were subjected to the buffers within $\mathrm{pH}$ range of 2-9 and recorded on spectrophotometer. The CuNPs showed no any convincing change in absorbance at $\mathrm{pH} \mathrm{2-4}$ and 7 but it gradually started to increase at $\mathrm{pH}$ range of 6 and $8-9$ with maximum change in plasmon at $\mathrm{pH} 8$. Similarly, $\mathrm{pH}$ of DEDTC functionalized CuNPs was examined at $490 \mathrm{~nm}$ and observed no any appreciable change in plasmon resonance, but $\mathrm{pH} 8$ was optimized for colorimetric determinations (Fig. 8). 
Table 1 Results obtained from quantitative determination of DTC Ziram, Zineb, and Maneb pesticides

\begin{tabular}{llccccc}
\hline S. no. & Pesticide & Calibration range $(\mathrm{ng} / \mathrm{ml})$ & $\mathrm{LOD}^{\mathrm{a}}(\mathrm{ng} / \mathrm{ml})$ & $\mathrm{LOQ}^{\mathrm{b}}(\mathrm{ng} / \mathrm{ml})$ & $\begin{array}{l}\text { Coefficient of } \\
\text { determination }\left(r^{2}\right)\end{array}$ & \begin{tabular}{l} 
Linear regression equation \\
\hline 01
\end{tabular} \\
& Ziram & $97.87-978.56$ & 150.9 & 457.5 & 0.9891 & $y=0.0006 x+0.4439$ \\
02 & Zineb & $8.82-88.25$ & 0.7 & 2.1 & 0.9951 & $y=0.0084 x+0.4331$ \\
03 & Maneb & $8.49-84.89$ & 6.1 & 18.5 & 0.9925 & $y=0.0056 x+0.484$ \\
\hline
\end{tabular}

${ }^{\mathrm{a}}$ Limit of detection

${ }^{\mathrm{b}}$ Limit of quantitation
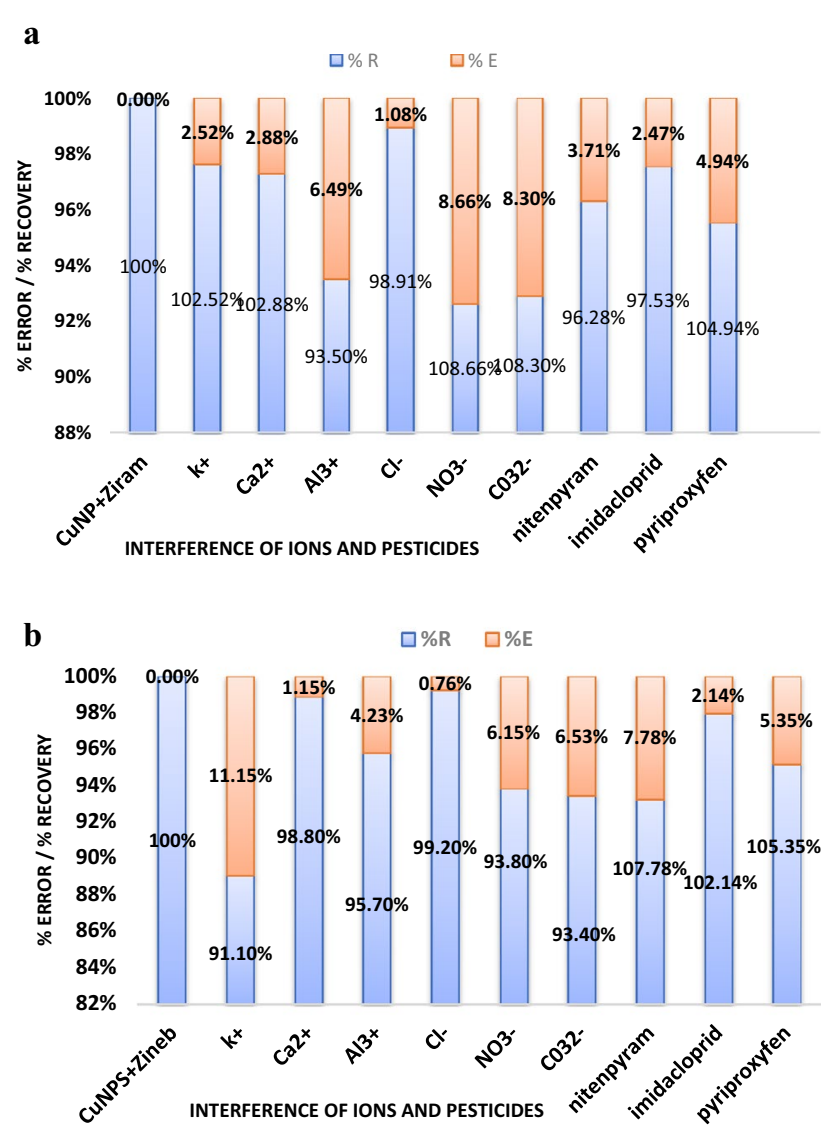

Fig. 11 Interference of different ionic moieties and pesticides on determination of DTCs

Time effect was inspected up to $3 \mathrm{~h}$ with intervals of 15 mints at $490 \mathrm{~nm}$ to investigate the duration of interaction with maximum stability. Initially an increase in absorbance was found which remained almost similar thereafter. Spectrum indicated a suitable time of $45 \mathrm{~min}$ to determine pesticides quantitatively because at this duration $\%$ error measured was less than 5\% (Fig. 9). The effects of $\mathrm{pH}$ and time were repeated atleast three times $(n=3)$.

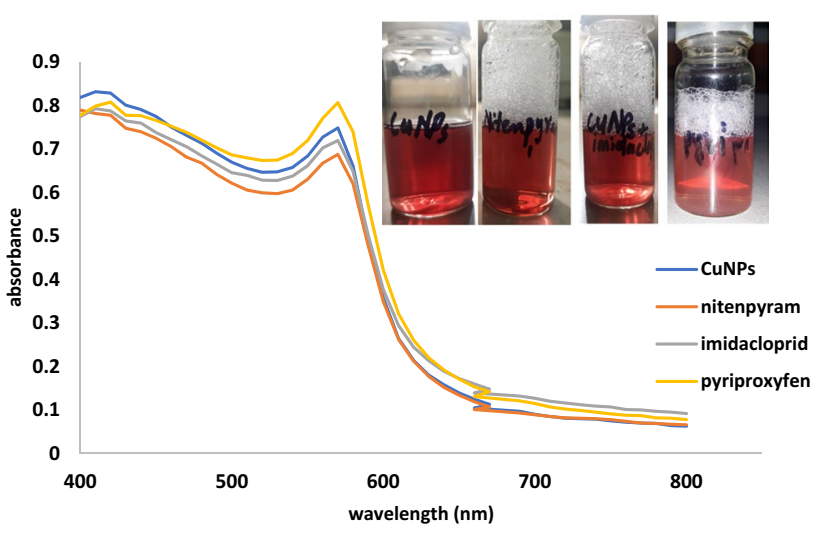

Fig. 12 Interaction of CTAB-CuNPs with different pesticides without DTCs

The quantitative determination of pesticides was made using probe CTAB-CuNPs within the linear calibration range $97.8-978.6 \mathrm{ng} / \mathrm{ml}, 8.8-88.2 \mathrm{ng} / \mathrm{ml}$ and $8.4-84.8 \mathrm{ng} /$ $\mathrm{ml}$ for Ziram, Zineb and Maneb, respectively, using seven calibrators (Fig. 10). Ziram contains a dithiocarbamate and Zineb and Maneb have bis-dithiocarbamate functionalities, thus Zineb and Maneb indicated better sensitivities than Ziram.

The gradual increase in absorption intensity was observed with the increase in concentration of pesticides at $490 \mathrm{~nm}$ or at ratio of $490 \mathrm{~A} / 570 \mathrm{~A}$. The linearity observed for Ziram, Zineb and Maneb were with coefficient of determination $\left(r^{2}\right)$ $0.989,0.995$ and 0.992 (Table 1).

The limit of detection and quantitation was calculated from standard deviation of the slope of the linear regression curve $(\mathrm{LOD}=3.3 \mathrm{Sa} / \mathrm{b}$ and $\mathrm{LOQ}=10 \mathrm{Sa} / \mathrm{b})$, where $\mathrm{Sa}=$ standard deviation and $\mathrm{b}=$ slope of calibration curve. The detection limit calculated for aforementioned pesticides were $150.9 \mathrm{ng} / \mathrm{ml}, 0.7 \mathrm{ng} / \mathrm{ml}, 6.1 \mathrm{ng} / \mathrm{ml}$ and quantitation limit calculated was $457.5 \mathrm{ng} / \mathrm{ml}, 2.1 \mathrm{ng} / \mathrm{ml}, 18.6 \mathrm{ng} / \mathrm{ml}$ for Ziram, Zineb and Maneb pesticides, respectively.

Selective sensing efficacy of probe was examined in presence of various ionic moieties such as $\mathrm{Ca}^{2+}, \mathrm{K}^{+}, \mathrm{Al}^{3+}, \mathrm{Cl}^{-}$, $\mathrm{CO}_{3}{ }^{2-}$ and $\mathrm{NO}_{3}{ }^{-}$at $5-100 \mathrm{ppm}$. Nevertheless, the study 
a

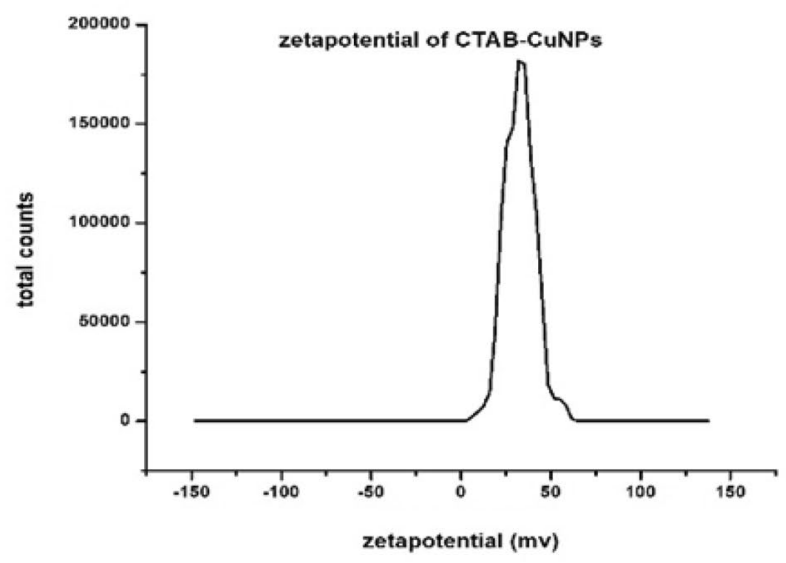

c

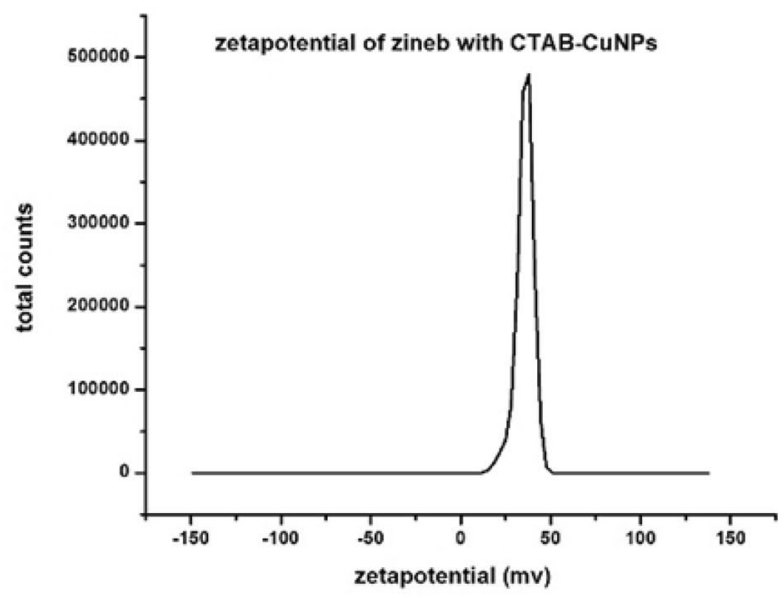

b

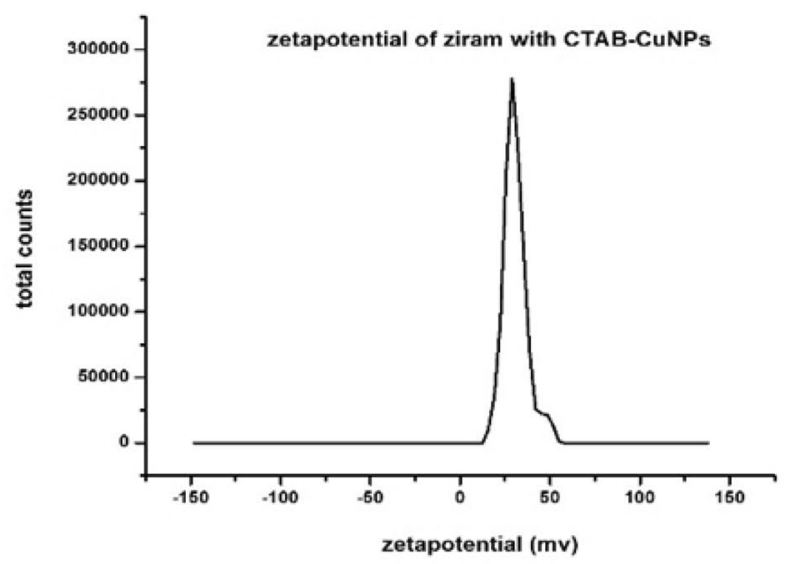

d

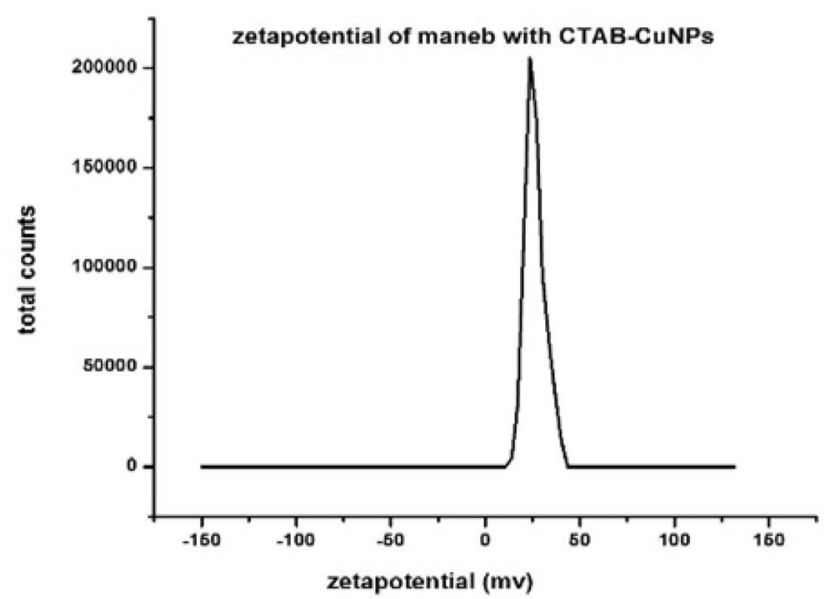

Fig. 13 Zeta potential measurement of (a) CTAB-CuNPs without adding DTCs and CTAB-CuNPs with addition of (b) Ziram (c) Zineb and (d) Maneb DTc pesticides

showed the interference of ionic species with relative error of $\pm 1.0-11.1 \%$ (Fig. 11). In addition selective assay for DTCs were also examined in presence of pesticides (nitenpyram, imidacloprid and pyriproxyfen). Their color change and surface plasmon (SPR) was investigated. As mentioned in (Fig. 12), their is no any shift in SPR at $570 \mathrm{~nm}$ in the spectrum of CTAB-CuNPs and color of the solutions also remained same (initially color change was seen but restored to same reddish wine after $10 \mathrm{~min}$ ) in presence of aforementioned pesticides $(10 \mathrm{ppm})$ without DTCs. Results showed no any cluster formation in presences of nitenpyram, imidacloprid and pyriproxyfen (10 ppm), which confirmed that they could not induce the aggregation of CTAB-CuNPs. But an apparent color change and spectra was observed with DTCs Ziram, Zineb and Maneb in presence of mixture of pesticides as mentioned in Fig. 2. The obtained results showed the interference of pesticides with relative error of $\pm 2.14-7.78 \%$ (Fig. 11). The developed method showed good selectivity towards DTCs over other pesticides. This showed that proposed probe acted as selective colorimetric sensor for DTCs over others.

The precision of probe to detect pesticides, samples were analyzed on the same day $(n=5)$ and with the day distances $(n=5)$. The \% RSD calculated was within $1.2-7.6 \%$.

The charge and size distribution was observed with nano-zetasizer Malvern instrument. The obtained data showed (Fig. 13a) surface of CTAB-CuNPs have a positive charge of about $32.5 \mathrm{mV}$. While that of Ziram, Zineb and Maneb have surface charge of $30.6 \mathrm{mV}, 35.6 \mathrm{mV}$ and $26.3 \mathrm{mV}$ (Fig. 13b-d). For a noticeably stable nanoparticles suspension through electrostatic repulsion, a zetapotential of $\pm 30 \mathrm{mV}$ is obligatory as minimum [53]. DLS is one of the most commonly used technique to determine the size of nanoparticles. It assesses the light dispersed from laser that passes through the colloidal solutions and then analyzed the modulated scattered light intensity as a function of time. 
$\mathbf{a}$

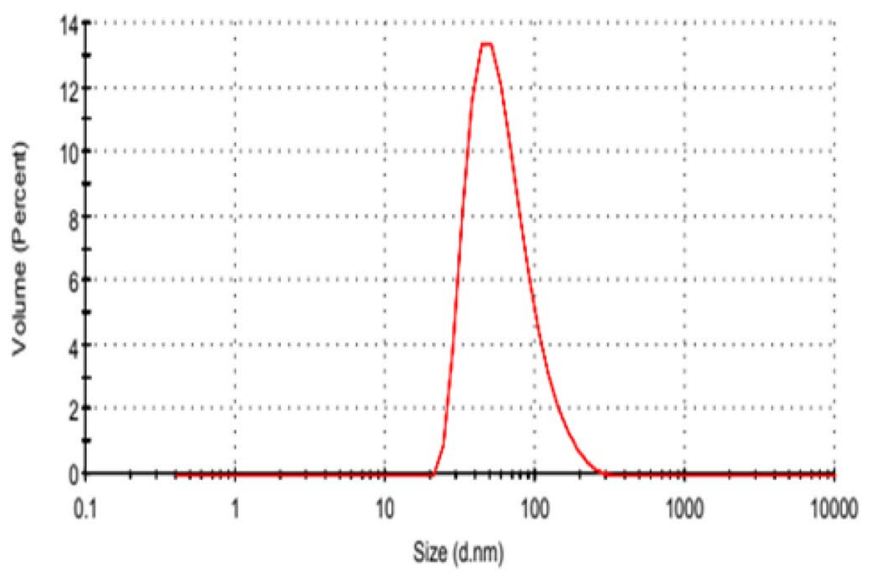

c

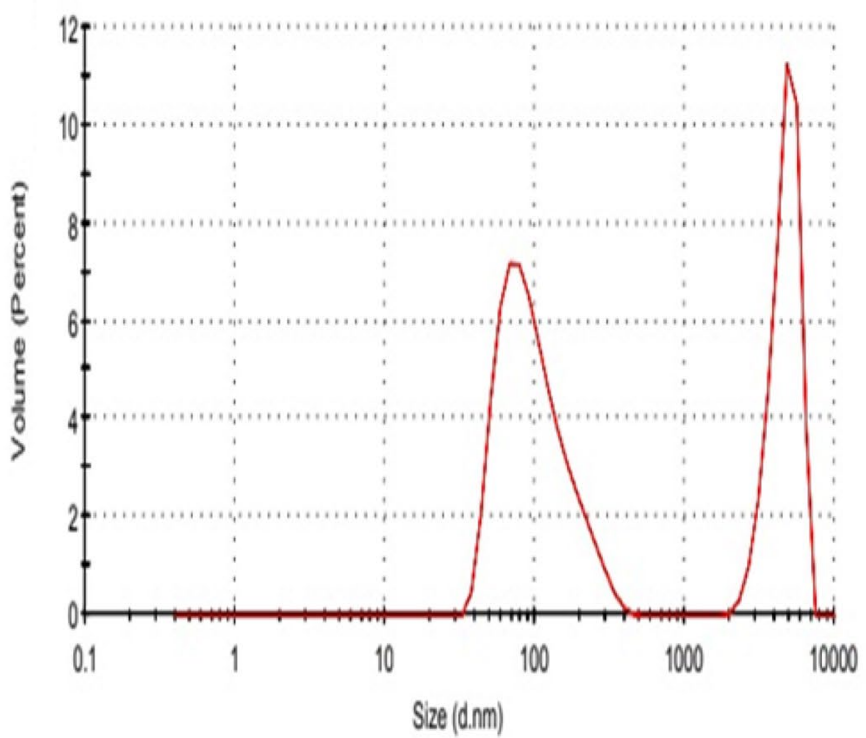

b

Size Distribution by Volume

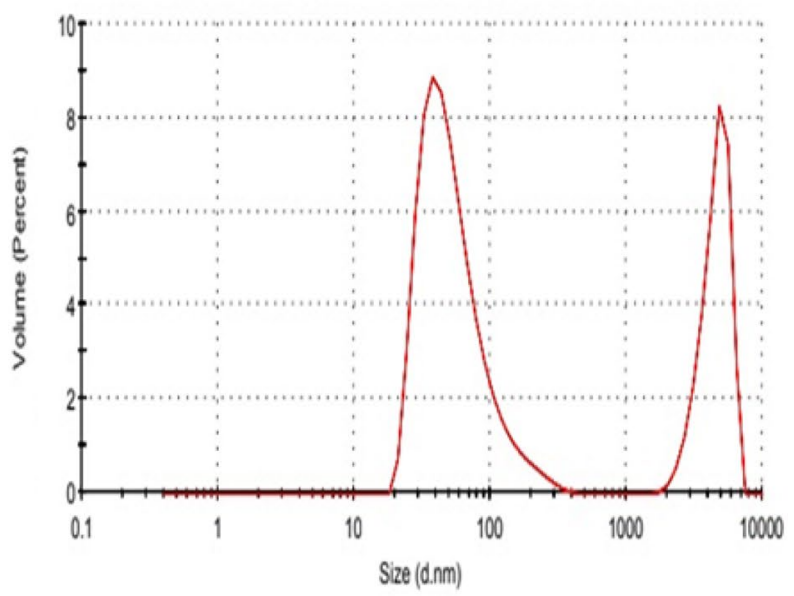

d

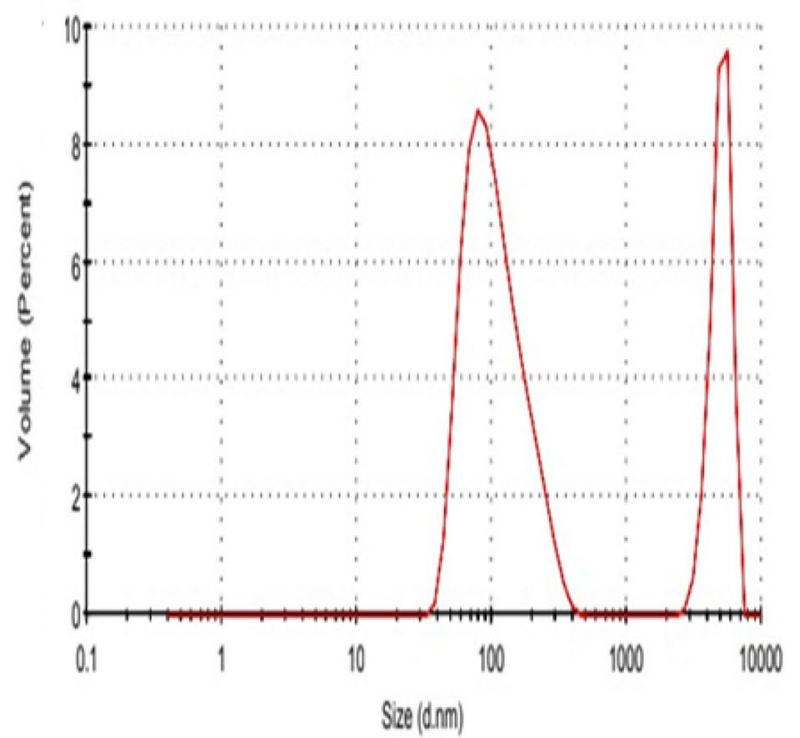

Fig. 14 Size distribution measurements of a CTAB-CuNPs and CTAB-CuNPs with b Ziram, $\mathbf{c}$ Zineb, $\mathbf{d}$ Maneb pesticides

Thus nanoparticle's hydrodynamic size can be determined $[54,55]$. The size distribution results (Fig. 14a) indicated the average size of $72.2 \mathrm{~nm}$ for CTAB-CuNPs with the polydispersive index of 0.233 at the measurement position of $5.50 \mathrm{~mm}$. Whereas mean average size obtained for Ziram, Zineb and Maneb were $83.1 \mathrm{~nm}, 111.3 \mathrm{~nm}$ and $125.2 \mathrm{~nm}$ with the polydispersive index $<1$ (Fig. 14b-d).

The practical application of probe was evaluated for determination of DTC pesticides in environmental samples (tap water) and juice sample (tomato vegetable and commercial mango drink) using analytical procedure. The results showed the recovery for Ziram was 95.8-108.5\% with RSD $(n=3)$ of $0.16-1.11 \%$ and \% error not over then $\pm 0.29-8.56$, for Zineb recovery obtained was $100.7-106.2 \%, \operatorname{RSD}(n=3)$ was $0.14-0.63 \%$ and $\%$ error calculated was $\pm 0.69-6.25$. Finally results obtained for Maneb pesticides revealed recovery within $96.2-108.5$ with $\%$ RSD $(n=3)$ within $0.15-0.77$ and relative error was $0.90-8.56 \%$ (Table 2 ).

The established colorimetric procedure was compared with flow injection flame, atomic absorption, capillary electrophoretic, voltammetry methods and AuNPs assisted colorimetric published methods in terms of sensitivity and selectivity. The results indicated comparable or better performance in terms of LOD and range of linearity than reported procedures (Table 3 ). 
Table 2 Analysis of DTCs from real samples

\begin{tabular}{|c|c|c|c|c|c|c|c|}
\hline S. no. & Analyte & Sample & Added (ng/ml) & Found $(\mathrm{ng} / \mathrm{ml})$ & $\%$ Recovery & $\begin{array}{l}\text { Standard devia- } \\
\text { tion }(n=3)\end{array}$ & $\begin{array}{l}\text { \% Relative } \\
\text { standard devia- } \\
\text { tion }\end{array}$ \\
\hline \multirow[t]{15}{*}{1} & \multirow[t]{15}{*}{ Ziram } & \multirow[t]{5}{*}{ Tap water } & 97.87 & 101.39 & 103.6 & 0.0005 & 0.251 \\
\hline & & & 146.80 & 147.98 & 100.8 & 0.002 & 0.826 \\
\hline & & & 293.61 & 294.49 & 100.3 & 0.0005 & 0.199 \\
\hline & & & 391.48 & 412.22 & 105.3 & 0.001 & 0.341 \\
\hline & & & 489.35 & 520.66 & 106.4 & 0.001 & 0.418 \\
\hline & & \multirow[t]{5}{*}{ Tomato juice } & 97.87 & 101.83 & 104.0 & 0.0005 & 0.250 \\
\hline & & & 146.80 & 152.16 & 103.6 & 0.001 & 0.683 \\
\hline & & & 293.61 & 281.39 & 95.8 & 0.003 & 1.114 \\
\hline & & & 391.48 & 402.39 & 102.8 & 0.005 & 0.175 \\
\hline & & & 489.35 & 499.23 & 102.0 & 0.0005 & 0.165 \\
\hline & & \multirow[t]{5}{*}{ Commercial mango drink } & 97.87 & 106.24 & 108.5 & 0.001 & 0.415 \\
\hline & & & 146.80 & 155.76 & 106.1 & 0.0005 & 0.222 \\
\hline & & & 293.61 & 315.96 & 107.6 & 0.001 & 0.321 \\
\hline & & & 391.48 & 396.34 & 101.2 & 0.002 & 0.816 \\
\hline & & & 489.35 & 523.39 & 106.9 & 0.001 & 0.272 \\
\hline \multirow[t]{15}{*}{2} & \multirow[t]{15}{*}{ Zineb } & \multirow[t]{5}{*}{ Tap water } & 8.82 & 8.95 & 101.4 & 0.001 & 0.277 \\
\hline & & & 13.23 & 13.47 & 101.8 & 0.002 & 0.532 \\
\hline & & & 26.47 & 26.65 & 100.7 & 0.002 & 0.500 \\
\hline & & & 35.29 & 35.93 & 101.8 & 0.002 & 0.491 \\
\hline & & & 44.12 & 46.36 & 105.1 & 0.002 & 0.327 \\
\hline & & \multirow[t]{5}{*}{ Tomato juice } & 8.82 & 9.17 & 103.9 & 0.0005 & 0.243 \\
\hline & & & 13.23 & 13.74 & 103.9 & 0.001 & 0.383 \\
\hline & & & 26.47 & 26.71 & 100.9 & 0.002 & 0.625 \\
\hline & & & 35.29 & 36.28 & 102.8 & 0.001 & 0.419 \\
\hline & & & 44.12 & 44.57 & 101.1 & 0.0005 & 0.148 \\
\hline & & \multirow[t]{5}{*}{ Commercial mango drink } & 8.82 & 9.32 & 105.6 & 0.001 & 0.632 \\
\hline & & & 13.23 & 13.85 & 104.6 & 0.0005 & 0.213 \\
\hline & & & 26.47 & 27.63 & 104.4 & 0.001 & 0.461 \\
\hline & & & 35.29 & 37.47 & 106.2 & 0.0005 & 0.153 \\
\hline & & & 44.12 & 45.37 & 102.8 & 0.0005 & 0.145 \\
\hline \multirow[t]{15}{*}{3} & \multirow[t]{15}{*}{ Maneb } & \multirow[t]{5}{*}{ Tap water } & 8.49 & 8.90 & 104.9 & 0.001 & 0.335 \\
\hline & & & 12.73 & 12.25 & 96.2 & 0.001 & 0.374 \\
\hline & & & 25.46 & 26.32 & 103.4 & 0.001 & 0.258 \\
\hline & & & 33.96 & 34.43 & 101.4 & 0.001 & 0.237 \\
\hline & & & 42.44 & 42.06 & 99.1 & 0.001 & 0.343 \\
\hline & & \multirow[t]{5}{*}{ Tomato juice } & 8.49 & 8.86 & 104.4 & 0.001 & 0.447 \\
\hline & & & 12.73 & 13.42 & 105.4 & 0.0005 & 0.210 \\
\hline & & & 25.46 & 26.22 & 102.9 & 0.001 & 0.493 \\
\hline & & & 33.96 & 34.36 & 101.2 & 0.001 & 0.518 \\
\hline & & & 42.44 & 43.28 & 101.9 & 0.002 & 0.555 \\
\hline & & \multirow[t]{5}{*}{ Commercial mango drink } & 8.49 & 9.04 & 108.5 & 0.002 & 0.763 \\
\hline & & & 12.73 & 13.90 & 106.1 & 0.0005 & 0.198 \\
\hline & & & 25.46 & 27.06 & 107.6 & 0.001 & 0.475 \\
\hline & & & 33.96 & 35.08 & 101.2 & 0.001 & 0.293 \\
\hline & & & 42.44 & 44.36 & 106.9 & 0.0005 & 0.156 \\
\hline
\end{tabular}


Table 3 Comparison of present work with published work

\begin{tabular}{|c|c|c|c|c|c|c|}
\hline S. no. & Technique/method & Analyte & $\begin{array}{l}\text { Calibration } \\
\text { range }(\mathrm{ng} / \mathrm{ml})\end{array}$ & Matrix & LOD (ng /ml) & References \\
\hline \multirow[t]{2}{*}{1} & \multirow[t]{2}{*}{ C.E method ${ }^{\mathrm{a}}$} & Ziram & $570-612,000$ & \multirow[t]{2}{*}{ Wheat samples } & 570.0 & \multirow[t]{2}{*}{ [21] } \\
\hline & & Zineb & $680-415,000$ & & 680.0 & \\
\hline \multirow[t]{2}{*}{2} & \multirow[t]{2}{*}{ Colorimetery method using AuNPs } & Maneb & $50-250$ & \multirow[t]{2}{*}{ Environmental samples } & 10.6 & \multirow[t]{2}{*}[35]{} \\
\hline & & Ziram & $25-175$ & & 46.8 & \\
\hline 3 & FI/FAAS ${ }^{b}$ & Zineb & $2500-25,000$ & Commercial formulations & 1000.0 & {$[56]$} \\
\hline \multirow[t]{3}{*}{4} & \multirow[t]{3}{*}{$\mathrm{AdSV}^{\mathrm{c}}$} & Maneb & $5-750$ & \multirow[t]{3}{*}{ Commercial formulations } & 2.0 & \multirow[t]{3}{*}{ [57] } \\
\hline & & Zineb & & & 7.4 & \\
\hline & & Zram & & & 14.0 & \\
\hline \multirow[t]{3}{*}{5} & \multirow[t]{3}{*}{ Colorimetric method using AgNPs } & Ziram & $195.7-733.9$ & \multirow[t]{3}{*}{ Environmental samples } & 149.3 & \multirow[t]{3}{*}{ [37] } \\
\hline & & Zineb & $17.6-66.1$ & & 4.0 & \\
\hline & & Maneb & $16.9-63.6$ & & 9.1 & \\
\hline \multirow[t]{3}{*}{6} & \multirow[t]{3}{*}{ Colorimetric method using CTAB-CuNPs } & Ziram & $97.87-489.35$ & \multirow[t]{3}{*}{ Environmental samples } & 150.9 & \multirow[t]{3}{*}{ Present work } \\
\hline & & Zineb & $8.82-44.12$ & & 0.7 & \\
\hline & & Maneb & $8.49-42.45$ & & 6.1 & \\
\hline
\end{tabular}

${ }^{\text {a }}$ Capillary electrophoresis

${ }^{\mathrm{b}}$ Flow injection/flame atomic absorption spectrometry

${ }^{\mathrm{c}}$ Adaptive stripping voltammetry

\section{Conclusion}

The preparation of stable CuNPs was achieved without any inert atmosphere using hydrazine monohydrate and CTAB. This simple, rapid and cheaper probe was highly sensitive to the dithiocarbamate pesticides with LOD 0.7-150.9 ng/ $\mathrm{ml}$ and \% recoveries calculated for environmental samples were in between 95.8 and $108.5 \%$ without the use of any sophisticated instruments. CuNPs have been examined for the analysis of Ziram, Zineb and Maneb, but the method could be extended similarly for the determination of DTCs like Mancozeb, Nabam, Metiram, Propineb and Ferbam.

Taking into consideration the gold and silver nanoparticles, the copper nanoparticles are thought to be most cost effective for the routine analysis of dithiocarbamate pesticides.

Acknowledgements We are highly thankful to the Institute of Advanced Research Studies in Chemical Sciences University of Sindh Jamshoro for supporting the Research project.

Open Access This article is distributed under the terms of the Creative Commons Attribution 4.0 International License (http://creativeco mmons.org/licenses/by/4.0/), which permits unrestricted use, distribution, and reproduction in any medium, provided you give appropriate credit to the original author(s) and the source, provide a link to the Creative Commons license, and indicate if changes were made.

\section{References}

1. Rycenga, M., Cobley, C.M., Zeng, J., Li, W., Moran, C.H., Zhang, Q., Qin, D., Xia, Y.: Controlling the synthesis and assembly of silver nanostructures for plasmonic applications. Chem. Rev. 111(6), 3669-3712 (2011)

2. Qin, L., Zeng, G., Lai, C., Huang, D., Zhang, C., Xu, P., Hu, T., Liu, X., Cheng, M., Liu, Y., Hu, L., Zhou, Y.: A visual application of gold nanoparticles: simple, reliable and sensitive detection of kanamycin based on hydrogen-bonding recognition. Sens. Actuators B Chem. 243, 946-954 (2017)

3. Lai, C., Liu, X., Qin, L., Zhang, C., Zeng, G., Huang, D., Cheng, M., Xu, P., Yi, H., Huang, D.: Chitosan-wrapped gold nanoparticles for hydrogen-bonding recognition and colorimetric determination of the antibiotic kanamycin. Microchim. Acta 184(7), 2097-2105 (2017)

4. Qin, L., Zeng, G., Lai, C., Huang, D., Xu, P., Zhang, C., Cheng, M., Liu, X., Liu, S., Li, B., Yi, H.: "Gold rush" in modern science: fabrication strategies and typical advanced applications of gold nanoparticles in sensing. Coord. Chem. Rev. 359, 1-31 (2018)

5. Kailasa, S.K., Koduru, J.R., Desai, M.L., Park, T.J., Singhal, R.K., Basu, H.: Recent progress on surface chemistry of plasmonic metal nanoparticles for colorimetric assay of drugs in pharmaceutical and biological samples. TrAC Trends Anal. Chem. 105, 106-120 (2018)

6. Du, S.Y., Li, Z.Y.: Enhanced light absorption of $\mathrm{TiO}_{2}$ in the nearultraviolet band by Au nanoparticles. Opt. Lett. 35(20), 34023404 (2010)

7. Jain, P.K., Huang, X., El-Sayed, I.H., El-Sayed, M.A.: Noble metals on the nanoscale: optical and photothermal properties and some applications in imaging, sensing, biology, and medicine. Acc. Chem. Res. 41(12), 1578-1586 (2008)

8. Glavee, G.N., Klabunde, K.J., Sorensen, C.M., Hadjipanayis, G.C.: Borohydride reduction of cobalt ions in water. Chemistry leading to nanoscale metal, boride, or borate particles. Langmuir 9(1), 162-169 (1993) 
9. Liz-Marzán, L.M., Lado-Touriño, I.: Reduction and stabilization of silver nanoparticles in ethanol by nonionic surfactants. Langmuir 12(15), 3585-3589 (1996)

10. Yu, Y.Y., Chang, S.S., Lee, C.L., Wang, C.C.: Gold nanorods: electrochemical synthesis and optical properties. J. Phys. Chem. B 101(34), 6661-6664 (1997)

11. Jana, N.R., Gearheart, L., Murphy, C.J.: Evidence for seed-mediated nucleation in the chemical reduction of gold salts to gold nanoparticles. Chem. Mater. 13(7), 2313-2322 (2001)

12. Patel, K., Kapoor, S., Dave, D.P., Mukherjee, T.: Synthesis of nanosized silver colloids by microwave dielectric heating. J. Chem. Sci. 117(1), 53-60 (2005)

13. Gawande, M.B., Goswami, A., Felpin, F.X., Asefa, T., Huang, X., Silva, R., Zou, X., Zboril, R., Varma, R.S.: $\mathrm{Cu}$ and $\mathrm{Cu}$-based nanoparticles: synthesis and applications in catalysis. Chem. Rev. 116(6), 3722-3811 (2016)

14. Ojha, N.K., Zyryanov, G.V., Majee, A., Charushin, V.N., Chupakhin, O.N., Santra, S.: Copper nanoparticles as inexpensive and efficient catalyst: a valuable contribution in organic synthesis. Coord. Chem. Rev. 353, 1-57 (2017)

15. Wang, D., Astruc, D.: The recent development of efficient Earthabundant transition-metal nanocatalysts. Chem. Soc. Rev. 46(3), 816-854 (2017)

16. Ahmed, K.B.A., Sengan, M., Kumar, S., Veerappan, A.: Highly selective colorimetric cysteine sensor based on the formation of cysteine layer on copper nanoparticles. Sens. Actuators B Chem. 233, 431-437 (2016)

17. Xia, X., Xie, C., Cai, S., Yang, Z., Yang, X.: Corrosion characteristics of copper microparticles and copper nanoparticles in distilled water. Corros. Sci. 48(12), 3924-3932 (2006)

18. Magdassi, S., Grouchko, M., Kamyshny, A.: Copper nanoparticles for printed electronics: routes towards achieving oxidation stability. Materials 3(9), 4626-4638 (2010)

19. Delepine, M.: Metallic salts of dithiocarbamic acids; preparation of isothiocyanates in aliphatic series. C. R. 144, 1125-1127 (1907)

20. Malik, A.K., Faubel, W.: Methods of analysis of dithiocarbamate pesticides: a review. Pestic. Sci. 55(10), 965-970 (1999)

21. Al-Alam, J., Bom, L., Chbani, A., Fajloun, Z., Millet, M.: Analysis of dithiocarbamate fungicides in vegetable matrices using HPLCUV followed by atomic absorption spectrometry. J. Chromatogr. Sci. 55(4), 429-435 (2017)

22. WHO. Dithiocarbamate pesticides, ethylenethiourea and propylenethiourea: a general introduction. International Program On Chemical Safety. http://www.inchem.org/documents/ehc/ehc/ ehc78.htm. Accessed 1998

23. WHO: The WHO Recommended Classification of Pesticides by Hazards and Guidelines to Classification. WHO/IPCS/IOMC, Geneva (2005)

24. Szolar, O.H.J.: Environmental and pharmaceutical analysis of dithiocarbamates. Anal. Chim. Acta 582(2), 191-200 (2007)

25. Kanchi, S., Singh, P., Bisetty, K.: Dithiocarbamates as hazardous remediation agent: a critical review on progress in environmental chemistry for inorganic species studies of 20th century. Arab. J. Chem. 7(1), 11-25 (2014)

26. Crnogorac, G., Schwack, W.: Residue analysis of dithiocarbamate fungicides. TrAC Trends Anal. Chem. 28(1), 40-50 (2009)

27. Ringli, D., Schwack, W.: Selective determination of thiram residues in fruit and vegetables by hydrophilic interaction LC-MS. Food Addit. Contam. Part A 30(11), 1909-1917 (2013)

28. Schmidt, B., Christensen, H.B., Petersen, A., Sloth, J.J., Poulsen, M.E.: Method validation and analysis of nine dithiocarbamates in fruits and vegetables by LC-MS/MS. Food Addit. Contam. Part A 30(7), 1287-1298 (2013)

29. Song, S., Wei, J., Chen, Z., Lei, Y., Zhang, Y., Deng, C., Tan, H., Li, X.: Determination of propineb and its metabolites propylenethiourea and propylenediamine in banana and soil using gas chromatography with flame photometric detection and LCMS/MS analysis. J. Environ. Sci. Health Part B 53(3), 153-160 (2018)

30. Cajka, T., Riddellova, K., Zomer, P., Mol, H., Hajslova, J.: Direct analysis of dithiocarbamate fungicides in fruit by ambient mass spectrometry. Food Addit. Contam. Part A 28(10), 1372-1382 (2011)

31. Oellig, C., Schwack, W.: Comparison of HILIC columns for residue analysis of dithiocarbamate fungicides. J. Liq. Chromatogr. Relat. Technol. 40(8), 415-418 (2017)

32. López-Fernández, O., Rial-Otero, R., González-Barreiro, C., Simal-Gándara, J.: Surveillance of fungicidal dithiocarbamate residues in fruits and vegetables. Food Chem. 134(1), 366-374 (2012)

33. Rastegarzadeh, S., Abdali, S.: Colorimetric determination of thiram based on formation of gold nanoparticles using ascorbic acid. Talanta 104, 22-26 (2013)

34. Giannoulis, K.M., Giokas, D.L., Tsogas, G.Z., Vlessidis, A.G.: Ligand-free gold nanoparticles as colorimetric probes for the nondestructive determination of total dithiocarbamate pesticides after solid phase extraction. Talanta 119, 276-283 (2014)

35. Rohit, J.V., Solanki, J.N., Kailasa, S.K.: Surface modification of silver nanoparticles with dopamine dithiocarbamate for selective colorimetric sensing of mancozeb in environmental samples. Sens. Actuators B Chem. 200, 219-226 (2014)

36. Rohit, J.V., Kailasa, S.K.: Cyclen dithiocarbamate-functionalized silver nanoparticles as a probe for colorimetric sensing of thiram and paraquat pesticides via host-guest chemistry. J. Nanopart. Res. 16(11), 2585 (2014)

37. Ghoto, S.A., Khuhawar, M.Y., Jahangir, T.M.: Silver nanoparticles with sodium dodecyl sulfate as colorimetric probe for detection of dithiocarbamate pesticides in environmental samples. Anal. Sci. (2019). https://doi.org/10.2116/analsci.18P41718P417

38. Hatamie, A., Zargar, B., Jalali, A.: Copper nanoparticles: a new colorimetric probe for quick, naked-eye detection of sulfide ions in water samples. Talanta 121, 234-238 (2014)

39. Schubart, R.: Dithiocarbamic acid and derivatives. In: Ullmann's Encyclopedia of Industrial Chemistry (2000). https://doi. org/10.1002/14356007.a09_001

40. Bhamore, J.R., Ganguly, P., Kailasa, S.K.: Molecular assembly of 3-mercaptopropinonic acid and guanidine acetic acid on silver nanoparticles for selective colorimetric detection of triazophos in water and food samples. Sens. Actuators B Chem. 233, 486-495 (2016)

41. Qi, L., Xu, Z., Jiang, X., Hu, C., Zou, X.: Preparation and antibacterial activity of chitosan nanoparticles. Carbohydr. Res. 339(16), 2693-2700 (2004)

42. Ribeiro, S., Hussain, N., Florence, A.T.: Release of DNA from dendriplexes encapsulated in PLGA nanoparticles. Int. J. Pharm. 298(2), 354-360 (2005)

43. Jeong, S., Woo, K., Kim, D., Lim, S., Kim, J.S., Shin, H., Moon, J.: Controlling the thickness of the surface oxide layer on $\mathrm{Cu}$ nanoparticles for the fabrication of conductive structures by ink-jet printing. Adv. Funct. Mater. 18(5), 679-686 (2008)

44. Chen, S., Sommers, J.M.: Alkanethiolate-protected copper nanoparticles: spectroscopy, electrochemistry, and solid-state morphological evolution. J. Phys. Chem. B 105(37), 8816-8820 (2001)

45. Chen, S., Fan, Z., Carroll, D.L.: Silver nanodisks: synthesis, characterization, and self-assembly. J. Phys. Chem. B 106(42), 10777-10781 (2002)

46. Elfeky, S.A., Mahmoud, S.E., Youssef, A.F.: Applications of CTAB modified magnetic nanoparticles for removal of chromium (VI) from contaminated water. J. Adv. Res. 8(4), 435-443 (2017) 
47. Biçer, M., Şişman, İ.: Controlled synthesis of copper nano/microstructures using ascorbic acid in aqueous CTAB solution. Powder Technol. 198(2), 279-284 (2010)

48. Dai, X., Xu, W., Zhang, T., Wang, T.: Self-reducible Cu nanoparticles for conductive inks. Ind. Eng. Chem. Res. 57(7), 2508-2516 (2018)

49. Sharma, J., Chhabra, R., Yan, H., Liu, Y.: A facile in situ generation of dithiocarbamate ligands for stable gold nanoparticle-oligonucleotide conjugates. Chem. Commun. 18, 2140-2142 (2008)

50. Saute, B., Premasiri, R., Ziegler, L., Narayanan, R.: Gold nanorods as surface enhanced Raman spectroscopy substrates for sensitive and selective detection of ultra-low levels of dithiocarbamate pesticides. Analyst 137(21), 5082-5087 (2012)

51. Rayavarapu, R.G., Petersen, W., Hartsuiker, L., Chin, P., Janssen, H., Van Leeuwen, F.W., Otto, C., Manohar, S., Van Leeuwen, T.G.: In vitro toxicity studies of polymer-coated gold nanorods. Nanotechnology 21(14), 145101 (2010)

52. Gölcü, A.: Transition metal complexes of propranolol dithiocarbamate: synthesis, characterization, analytical properties and biological activity. Transit. Met. Chem. 31(3), 405-412 (2006)

53. Singare, D.S., Marella, S., Gowthamrajan, K., Kulkarni, G.T., Vooturi, R., Rao, P.S.: Optimization of formulation and process variable of nanosuspension: an industrial perspective. Int. J. Pharm. 402(1-2), 213-220 (2010)

54. Koppel, D.E.: Analysis of macromolecular polydispersity in intensity correlation spectroscopy: the method of cumulants. J. Chem. Phys. 57(11), 4814-4820 (1972)

55. Berne, B.I., Recora, R.: Dynamic Light Scattering with Applications to Chemistry, Biology and Physics. Dover Publications Inc, Minneola (2000)

56. Cassella, R.J., Salim, V.A., Garrigues, S., Santelli, R.E., de la Guardia, M.: Flow injection/atomic absorption spectrometric determination of zineb in commercial formulations of pesticide based on slurry sampling. Anal. Sci. 18(11), 1253-1256 (2002)

57. Amorello, D., Orecchio, S.: Micro-determination of dithiocarbamates in pesticide formulations using voltammetry. Microchem. J. 110, 334-339 (2013)

Publisher's Note Springer Nature remains neutral with regard to jurisdictional claims in published maps and institutional affiliations. 